\title{
Phase-sensitive radar as a tool for measuring firn compaction
}

\section{Article}

Cite this article: Case E, Kingslake J (2022). Phase-sensitive radar as a tool for measuring firn compaction. Journal of Glaciology 68(267), 139-152. https://doi.org/10.1017/jog.2021.83

Received: 22 December 2020

Revised: 9 June 2021

Accepted: 14 June 2021

First published online: 17 August 2021

\section{Key words:}

Glacier geophysics; glaciological instruments and methods; ice rise; polar firn; radio-echo sounding

\section{Abbreviations:}

ApRES: autonomous phase-sensitive radioecho sounder; FP: Fletcher Promontory; GNSS Global Navigation System Satellite; KIR: Korff Ice Rise; pRES: phase-sensitive radio-echo sounder; SIR: Skytrain Ice Rise

\section{Author for correspondence:}

Elizabeth Case, E-mail: ehc2150@columbia. edu

(c) The Author(s), 2021. Published by Cambridge University Press. This is an Open Access article, distributed under the terms of the Creative Commons Attribution licence (http://creativecommons.org/licenses/by/4.0/), which permits unrestricted re-use, distribution, and reproduction in any medium, provided the original work is properly cited.

\section{Elizabeth Case ${ }^{1,2}$ (D) and Jonathan Kingslake $e^{1,2}$ (D)}

${ }^{1}$ Department of Earth and Environmental Sciences, Columbia University, New York, NY, USA and ${ }^{2}$ Lamont Doherty Earth Observatory, Palisades, NY, USA

\section{Abstract}

Firn compaction models inform mass-balance estimates and paleo-climate reconstructions, but current models introduce key uncertainties. For example, models disagree on the dependence of density and compaction on accumulation rate. Observations of compaction to test these models are rare, partly because in situ methods for measuring englacial strain are time-consuming and expensive. Moreover, shallow measurements may confound strain due to compaction with strain due to ice-sheet flow. We show that phase-sensitive radio-echo sounder (pRES) systems, typically deployed to measure sub-shelf melting or ice-sheet deformation, can be used to measure firn compaction and test firn models. We present two complementary methods for extracting compaction information from pRES data, along with a method for comparing compaction models to pRES observations. The methods make different assumptions about the density structure and vary in their need for independent density measurements. Compaction profiles computed from pRES data collected on three ice rises in West Antarctica are largely consistent with measured densities and a physics-based model. With their minimal logistic requirements, new pRES systems, such as autonomous pRES, could be inexpensively deployed to monitor firn compaction more widely. Existing phase-sensitive radar data may contain compaction information even when surveys targeted other processes.

\section{Introduction}

Firn is partially metamorphosed snow that has survived at least 1 year on an ice-sheet or glacier surface. Densification turns fresh snow into firn and firn into glacial ice. An understanding of firn densification is vital for constraining past, present and future climate and ice-sheet change for two key reasons.

Firstly, firn densification introduces uncertainty into altimetric mass-balance estimates. Firn densification rates change in response to temperature, accumulation rate and melting/ refreezing (e.g. de la Peña and others, 2015) on timescales of days to millennia (Arthern and Wingham, 1998; Li and Zwally, 2002; Li and others, 2007). Changing densification rates raise or lower ice surfaces without affecting the total ice mass, so must be accounted for when computing mass changes from volumetric changes measured by satellite altimetry (e.g. Shepherd and others, 2012; Hanna and others, 2013). Helsen and others (2008) suggest that surface-height changes associated with the impact of temperature and accumulation on firn densification were the same order of magnitude as those observed by altimetry over East Antarctica between 1980 and 2004. More recently, Smith and others (2020) modeled changes in the densification rate on the order of surface height changes measured by ICESat-2 in 2018-19 in some Antarctic drainage basins (their Fig. S8). These densification rate changes are transient; Ligtenberg and others (2014) suggest that using a steady-state firn densification model can underestimate Antarctic mass loss by up to $23 \%$ compared to a time-dependent model.

Secondly, firn densification affects the ice-age-gas-age offset in ice cores (Craig and others, 1988; Bender and others, 1997; Severinghaus and Brook, 1999). Above the lock-in zone, air in the firn mixes with the atmosphere, so air bubbles in glacial ice are younger than the surrounding ice crystals. This complicates paleo-climate interpretations because the uncertainty in the age offset can be large compared to the timescales of climate variability (Buizert and others, 2015; WAIS Divide Project Members, 2015). To quantify the impact of firn densification on mass-balance estimates and gas age in ice cores, we turn to physics-based models.

In polar settings, most firn densification occurs through dry compaction. Snow is buried by subsequent accumulation, and the overlying weight squeezes the ice grains together and pushes air out. Dry compaction processes include grain packing, grain deformation and sintering (Alley and others, 1982; Cuffey and Paterson, 2010). Many physics-based models of dry firn compaction exist (Lundin and others, 2017). Most models employ an Arrhenius dependence of compaction on temperature, but disagree on the magnitude of the temperature sensitivity as well as the relationship between stress and strain, resulting in models displaying contrasting dependence on environmental factors such as temperature and accumulation rate (Lundin and others, 2017). For example, the widely used empirical model of Herron and Langway (1980) defines two density regimes and dependence on accumulation rate changes between these regimes. In contrast, Zwally and Li (2002) tuned an empirical model to experimental results, suggesting a higher temperature sensitivity and no distinct density regimes. Arthern 
and others (2010) derived a model that includes grain-size evolution and was tuned to near-surface strain rate measurements. Due to the counteracting effects of advection of grain size and of density, the model of Arthern and others (2010) produces steady-state density profiles that are weakly dependent on the accumulation rate (Lundin and others, 2017) - a prediction that disagrees with the conclusions of some observational studies (e.g. Ligtenberg and others, 2014; Morris and others, 2017). Other models describe compaction that depends variously on different grain-scale processes, bulk stresses, permeability and impurity content (Alley, 1987; Arnaud and others, 2000; Goujon and others, 2003; Salamatin and others, 2009; Arthern and others, 2010; Meyer and others, 2020), leading to wide variability in model dependence on environmental factors (Lundin and others, 2017).

One barrier to reconciling these disagreements is the scarcity of compaction observations. Most measurements of near-surface vertical strain rates involve borehole instrumentation, which is time-consuming and expensive to install. Consequently, firn densification models are usually tuned to density measurements. Exceptions include models tuned to measurements from strain gauges (Arthern and others, 2010), repeat neutron probe measurements of density (Morris and Wingham, 2014; Morris and others, 2017; Morris, 2018) and airborne radar (Medley and others, 2015).

Here, we explore the use of a ground-based phase-sensitive radio-echo sounder ( $\mathrm{pRES}$ ) to measure densification rates following initial research by Jenkins and others (2006). pRES was first developed to measure basal melt rates on ice shelves (Corr and others, 2002; Jenkins and others, 2006; Brennan and others, 2014; Nicholls and others, 2015), but has since been extended to investigate ice dynamics (Gillet-Chaulet and others, 2011; Kingslake and others, 2014, 2016), ice fabric (Jordan and others, 2020; Young and others, 2021) and englacial water storage (Kendrick and others, 2018; Vaňková and others, 2018).

Phase-sensitive radar can be used to estimate the total vertical strain rate in an ice column, which includes contributions from ice-sheet dynamics - the extension, compression and/or shearing due to ice-sheet flow - and from firn compaction. At our field sites, we assume these signals are additive and separable following others (e.g. Jenkins and others, 2006), and show that this assumption allows us to isolate firn compaction velocities from pRES observations that broadly agree with compaction rates simulated with a model based on Arthern and others (their Appendix B; 2010). Vertical strain rates are approximately uniform in a region below the firn and far from the bed (Raymond and others, 1996), and previous research has used a linear fit to pRES-derived vertical velocities in this part of the ice column to estimate nearsurface horizontal strain rates (Gillet-Chaulet and others, 2011; Kingslake and others, 2014). We take this approach here, building on Jenkins and others (2006), who found that the vertical strain that remained after removing the contribution of a uniform horizontal strain rate from pRES measurements matched densification rates derived from a simplified mass-balance equation and measurements of accumulation rate and near-surface density. They also found the horizontal divergence of ice flow to be a significant percentage of the measured total strain rates in the upper tens of meters of the ice column.

The paper is structured as follows. In Section 2, we describe our field sites and pRES deployment, two complementary methods for extracting compaction information from pRES data, a firn densification model (Arthern and others, 2010), and a method for comparing compaction models to pRES observations. These methods account for the complications of density-dependent radio-wave speed and the background strain rate associated with ice-sheet flow. Each method makes different assumptions about density structure, whether the firn is in steady state, and the availability of independent density measurements. The first two methods aim to estimate firn compaction from pRES measurements, and a third method allows for comparison between modeled compaction and pRES measurements but does not retrieve compaction measurements. In Section 3, we compare pRES-observed firn compaction to modeled compaction and compare modeled density profiles to ice-core measurements from two of our field sites. In Section 4, we discuss the advantages and limitations of our methods and discuss how existing data collected with pRES and its successor, autonomous pRES, may contain valuable information about firn compaction and its dependence on surface accumulation and temperature.

\section{Methods}

\subsection{Field sites, pRES survey design and ancillary data}

We deployed pRES on three ice rises in the Weddell Sea sector, West Antarctica: Korff Ice Rise (KIR), Fletcher Promontory (FP) and Skytrain Ice Rise (SIR) (Fig. 1a; Kingslake and others, 2014).

An ice divide runs the length of KIR, a slow-moving, 600-mthick area of grounded ice surrounded by the Ronne Ice Shelf. Kingslake and others (2016) suggest that the flow of KIR underwent a reorganization 1.9-2.9 ka ago, which is also evident in the ice fabric below the firn between 200 and $230 \mathrm{~m}$ (Brisbourne and others, 2019) and that it has remained approximately steady since this time. On 20-22 December 2013 and 5-7 December 2014, pRES was deployed at 35 locations (resulting in usable data from 33 locations), evenly spaced along a $4.4 \mathrm{~km}$ transect parallel to ice flow and perpendicular to the divide (Fig. 1b). A surface Global Navigation System Satellite (GNSS) survey measured horizontal surface velocities and showed that there is negligible flow parallel to the divide in this location (Kingslake and others, 2016). FP is a promontory-style ice rise (i.e. one which is connected to the main ice sheet by grounded ice; Matsuoka and others, 2015) with a triple-junction ice divide that generates a complex 3-D ice flow pattern (Hindmarsh and others, 2011). In conjunction with a wider survey (Kingslake and others, 2014), pRES measurements were taken at a single location $\left(-77.900^{\circ}\right.$, $-82.614^{\circ}$ ) on 25 January 2014 and 13 January $2015, \sim 300 \mathrm{~m}$ from the site of an ice core $\left(-77.902^{\circ},-82.605^{\circ}\right.$; Mulvaney and others, 2014). SIR, also a promontory-style ice rise, sits at the southwest edge of the Ronne Ice Shelf to the east of FP (Fig. 1). pRES was deployed at 31 points on 7-11 December 2013 and 8-11 January 2015 along a $5.2 \mathrm{~km}$ transect perpendicular to and crossing the divide, centered on the location of a full-depth ice core $\left(-79.741^{\circ},-78.545^{\circ}\right.$; Fig. 1c; personal communication from R. Mulvaney, 2021).

pRES is a stationary, step-frequency, ground-based radar system, which transmits and receives through two spatially separated antennas (Corr and others, 2002). This system is the predecessor to the autonomous phase-sensitive radio-echo sounder (ApRES; Nicholls and others, 2015). At each field site, the transmitting and receiving antennas were separated by $7 \mathrm{~m}$ and multiple measurements were made during each visit to each site while varying antenna orientations between measurements (for the full procedure see Kingslake and others, 2014, 2016). For the measurements on KIR and SIR, the antennas were oriented along and perpendicular to the transect lines (Figs 1b, c; note that the polarimetric surveys on KIR reported by Brisbourne and others (2019) were located $\sim 50 \mathrm{~km}$ north of our transect). To obtain measurements of vertical velocity, we made repeat measurements at each site separated by $\sim 1$ year. 

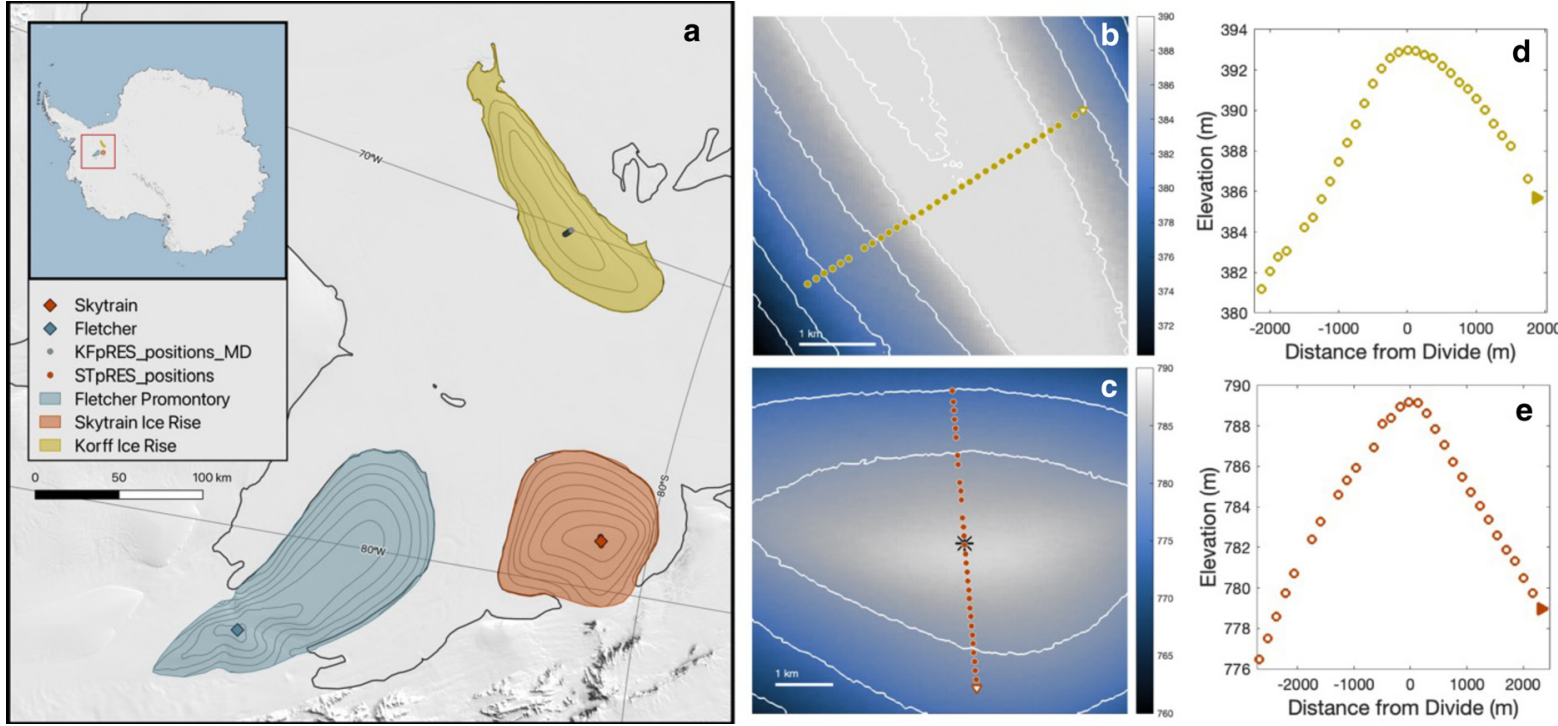

Fig. 1. Field sites and surveys. Panel a shows the location of FP, KIR and SIR field sites in the Weddell Sea sector, West Antarctica. A single pair of pRES measurements was made close to the site of a full-depth ice core on FP (blue). At SIR (orange), 34 measurement pairs were taken along a transect that crossed an ice divide and was centered on a second core site. At KIR (yellow), 35 measurement pairs were taken along a transect that crossed the ice divide. The background image is the MODIS mosaic of Antarctica (Haran and others, 2021), and the grounding line (MEaSUREs v2; Mouginot and others, 2017) is shown in black. The 100 $\mathrm{m}$ contours in gray on the ice rises in panel a are from the Radarsat Antarctic Mapping Project Digital Elevation Model, Version 2 (Helm and others, 2014). The middle plots show the transects along Korff (b, yellow) and Skytrain (c, orange) overlaying the Reference Elevation Model of Antarctica (REMA; Howat and others, 2019). On Skytrain (c), the location of the ice core is indicated by the black star. The triangles at one end of the transects in both panels $b$ and $c$ indicate the direction of the far-right plots $(\mathrm{d}, \mathrm{e})$, which show the elevation change and topography of the transect as interpolated from REMA.

Table 1. Climatic, ice core and pRES survey characteristics of the three field sites

\begin{tabular}{|c|c|c|c|c|c|}
\hline $\begin{array}{l}\text { Field } \\
\text { site }\end{array}$ & $\begin{array}{l}\text { RACMO accumulation } \\
\text { rate } \\
\text { mi.e. } a^{-1}\end{array}$ & $\begin{array}{l}\text { Ice core-derived } \\
\text { accumulation rate } \\
\text { m i.e. } a^{-1}\end{array}$ & $\begin{array}{l}\text { pRES-derived accumulation } \\
\text { rate } \\
\text { m i.e. } a^{-1}\end{array}$ & $\begin{array}{l}\text { Average surface } \\
\text { temperature } \\
{ }^{\circ} \mathrm{C}\end{array}$ & $\begin{array}{l}\text { Ice density average from ice-core } \\
\text { measurements } \\
\mathrm{kg} \mathrm{m}^{-3}\end{array}$ \\
\hline FP & $0.38 \pm 0.08$ & $0.30^{\mathrm{a}}$ & $0.41 \pm 0.01^{b}$ & $-27.1^{\mathrm{c}}$ & 906 \\
\hline SIR & $0.23 \pm 0.05$ & $0.15 \pm 0.02^{\mathrm{a}}$ & $0.10-0.16^{\mathrm{d}}$ & $-26.0^{c}$ & 907 \\
\hline KIR & $0.21 \pm 0.03$ & NA & $0.14-0.22^{d}$ & $-24.3^{\mathrm{e}}$ & NA \\
\hline
\end{tabular}

RACMO-simulated accumulation rates (in meters ice-equivalent) are 40-year averages over a $50 \mathrm{~km}^{2}$ radius area centered on each field site. The measured accumulation rates and temperatures for FP and SIR are from Mulvaney and others (2014) and personal communication from R. Mulvaney (2021), where accumulation rates are recent, multi-centennial averages ( 1000 years). Ice densities were measured in the field during drilling of ice cores on FP (Mulvaney and others, 2014) and SIR (personal communication from R. Mulvaney, 2020). The KIR average temperature is from a British Antarctic Survey automatic weather station (AWS) that took measurements between 2014 and 2017 (personal communication from R. Mulvaney, 2018 ). The pRES-derived accumulation rates are estimated assuming a steady state (Section 2.4).

${ }^{a}$ Multi-centennial-averaged accumulation rates.

${ }^{\mathrm{b}} \mathrm{Std}$ dev. estimated by varying bounds on linear fit.

${ }^{\mathrm{c}} 10-\mathrm{m}$ borehole temperature.

${ }^{\mathrm{d}}$ Range across the transect.

eAWS (1/2014-2/2017).

Table 1 summarizes ancillary data for each field site. We used the regional climate model RACMO2.3p2 (van Wessem and others, 2018) to estimate mean accumulation rates at each site. We averaged mean annual accumulation rates between 1979 and 2015 and over $50 \mathrm{~km}$ radius, circular areas centered on the core sites on FP and SIR, and the center of the transect on KIR (Wearing and Kingslake, 2019). At the two locations where ice cores have been drilled, FP and SIR, we used measured multi-centennial-averaged $(\sim 1000$ years $)$ accumulation rates and the density of ice equal to the mean density of the core between a depth of $250 \mathrm{~m}$ and the bed (personal communication from R. Mulvaney, 2020). These densities are less than the commonly used $917 \mathrm{~kg} \mathrm{~m}^{-3}$ (Table 1). We use average annual surface temperatures estimated from a weather station on KIR (personal communication from R. Mulvaney, 2018) and from 10-m borehole temperatures measured at SIR and FP (Mulvaney and others, $2014 ; 2021)$. We assume that $10-\mathrm{m}$ borehole temperatures represent the average annual air temperature.

\subsection{Phase-sensitive radio-echo sounder}

pRES measures the response of the ice sheet to a range of frequencies over a bandwidth of $160 \mathrm{MHz}$ centered on a frequency, $f_{\mathrm{c}}=305 \mathrm{MHz}$. At each frequency, the complex ratio between a transmitted and received signal is recorded. Following Corr and others (2002), an inverse Fourier transform of the frequency response yields power and phase as functions of two-way travel time, $T$.

To relate depth, $\zeta$, to $T$, we use

$$
\zeta(T)=\frac{c}{2} \int_{0}^{T} \frac{1}{n(\rho)} \mathrm{d} T,
$$

where $c$ is the speed of light in a vacuum $\left(2.998 \times 10^{8} \mathrm{~m} \mathrm{~s}^{-1}\right)$ and the refractive index, $n$, depends on density through 


$$
n(\rho)=1+\left(n_{\mathrm{i}}-1\right) \frac{\rho}{\rho_{\mathrm{i}}}
$$

where $\rho_{\mathrm{i}}$ is the density of ice (see Table 1 ) and $n_{\mathrm{i}}$ is the refractive index of ice (1.78) (see Kovacs and others (1995) for discussion of more complex and potentially more accurate relationships between $\rho$ and $n$ ). At different stages throughout our methods, we define $n$ using $\rho$ as a function of $\zeta$ or $T$, as implied by the integral in Eqn (1).

Following Corr and others, 2002, we assume that peaks in the pRES returns that persist between measurements move as material surfaces. We refer to these peaks as 'reflectors' even though they are generally assumed to be interference patterns resulting from many thinner layers, which are not explicitly resolved by the radar. Reflectors are chosen using an algorithm based on their brightness and phase coherence (for more details, see Corr and other, 2002; Kingslake and others, 2014). The distances between these reflectors change as firn compacts and the ice sheet flows. We track this by recording the relative phase $(\phi)$ of each reflector during two time-separated pRES measurements. For reflector $j$, we record $\phi_{1}^{j}$ and $\phi_{2}^{j}$ in the first and second deployments, respectively. We difference these with the phase of a reference reflector identified in both years $\phi_{1}^{\mathrm{R}}$ and $\phi_{2}^{\mathrm{R}}$ to remove the effect of vertical displacement of the radar between measurements. The reference reflector is arbitrarily chosen as one that lies close to $100 \mathrm{~m}$ depth and can be unambiguously identified in returns from both time-separated deployments (Kingslake and others, 2014).

If one assumes uniform density, these relative phase differences can be straight-forwardly expressed as a fraction of a wavelength and therefore a relative vertical displacement (e.g. Kingslake and others, 2014). As we are concerned with strain in the firn where $\rho$ varies vertically, we express changes in two-way travel time as a function of change in relative phase for each layer $j$ :

$$
\Delta T^{j}=\frac{\left(\phi_{2}^{j}-\phi_{1}^{j}\right)-\left(\phi_{2}^{\mathrm{R}}-\phi_{1}^{\mathrm{R}}\right)}{f_{\mathrm{c}}} .
$$

The phase changes can be measured to an accuracy of up to $\sim 1^{\circ}$, which translates into a $\Delta T$ on the order of nanoseconds. The uncertainty of each $\Delta T^{j}$ is estimated following Kingslake and others (2014; their Section 2.1). A reflector phasor is generated from the strength and phase of reflector $j$. It is combined with a noise phasor with a magnitude equal to the mean of the noise floor of the radar return and an assumed perpendicular orientation compared to the reflector phasor (corresponding to the maximum possible phase offset). This gives a conservative estimate of the uncertainty in the phase at each reflector. To increase the signal-to-noise ratio, the $\Delta T^{j}$ values are stacked into $\sim 10-\mathrm{m}(0.12 \mathrm{~ms})$ bins by calculating the mean in each bin weighted by the inverse square of the measurement uncertainties (Kingslake and others, 2016). The result is a profile of the change in two-way travel time as a function of the two-way travel time, $\Delta T(T)$.

\subsection{Two methods for extracting densification rates from $p R E S$ observations}

Here, we outline two methods to extract compaction rates from pRES data. For each method the key challenge is converting the quantities measured by pRES - two-way travel time, $T$, and change in relative two-way travel time, $\Delta T$ - into depth and compaction velocity. Method 1 uses densities measured from coincident ice cores to make these conversions. Method 2 uses a mass-conserving inverse method to estimate depth, compaction velocity and density. It does not require density measurements but assumes a steady-state exponential density profile. Note that we use different symbols to differentiate various vertical velocities: $W$ refers to velocities derived from $p R E S$ observations, $\omega$ refers to the vertical velocity minimized for in Method 2, and $w$ both refers to the vertical velocity modeled by the physics-based compaction model (Section 2.5) and is used generically in equations that apply to more than one vertical velocity. All variables are shown in Table 2.

\subsubsection{Method 1: compaction velocities using independently measured densities}

To translate $T$ into $\zeta$ for any particular reflector, we need to know the density at and above that reflector. We transform the depth of an ice core into $T$ using

$$
T(\zeta)=\frac{2}{c} \int_{0}^{\zeta} n(\rho(\zeta)) d \zeta
$$

and then use linear interpolation to estimate the ice-core-derived density at the $T$ of each binned pRES measurement.

The vertical velocity, $W$, of each englacial reflector relative to a reference reflector is computed as follows:

$$
W=\frac{\mathrm{c}}{n(\rho(T))} \frac{\Delta T}{\Delta \tau},
$$

where $\Delta \tau$ is the time between radar measurements. We then use Eqn (1) to compute $\zeta$ for each reflector in the pRES returns.

Following Jenkins and others (2006) and Morris and others (2017), we assume the total vertical velocity can be separated into two components: an ice-dynamic component, $W_{\mathrm{d}}$, generated by horizontal divergence or convergence of the ice sheet, and a vertical firn compaction component, $W_{\mathrm{c}}$. If $u$ represents horizontal velocity, mass conservation in the incompressible part of the ice column beneath the firn, $\partial u / \partial x+\partial w / \partial z=0$, allows us to estimate the horizontal strain rate, $\dot{\epsilon}_{x}=\partial u / \partial x$, from the pRES-measured vertical strain rate, $\dot{\epsilon}_{z}=\partial w / \partial z$, by assuming that all vertical velocities, and therefore all vertical strain rates, measured below the firn are due to horizontal convergence or divergence. Following Kingslake and others (2014), we assume contributions from $v$ and $\dot{\epsilon}_{y}=\partial v / \partial y$ are negligible along the flanks of ice rises. This approach is further simplified by assuming that the horizontal strain rate is constant in the top two-thirds of the ice column (above bed effects), and therefore $W_{\mathrm{d}}$ is linear, which is consistent with the shallow ice approximation (SIA; Lliboutry, 1979; Wearing and Kingslake, 2019). These assumptions allow us to estimate $W_{\mathrm{d}}$ using a linear least-squares fit to the pRES-measured $W$ (Eqn (4)) in the middle third of the ice column, below the firn-ice transition and above bed effects, and then extrapolate this fit to the surface, giving $W_{\mathrm{d}}$ in the ice and firn. At FP, we use $160<\zeta<309 \mathrm{~m}$ as the depth range for the linear fit, at SIR we use $122<\zeta<304 \mathrm{~m}$ and at KIR we use $150<\zeta<$ $300 \mathrm{~m}$. The boundaries for FP and SIR were chosen by minimizing the mismatch between the core density and the density inverted for in Method 2 (Section 2.3.2), although the ice-coremeasured densities could also be used to choose these bounds. We discuss the impact of the choice of upper and lower boundaries on the results in Section 4 . Once $W_{\mathrm{d}}$ is estimated, the compaction velocity, $W_{c}$, can be isolated by subtracting $W_{\mathrm{d}}$ from the observed radar velocity, $W_{\mathrm{c}}=W-W_{\mathrm{d}}$.

\subsubsection{Method 2: inverting for density and vertical velocity}

Method 2 addresses a common scenario where we have pRES observations without coincident density measurements. In this case, we must estimate $n(\rho)$ to obtain vertical velocities from Eqn (4). We estimate $\rho$ by solving the compressible mass conservation equation for the vertical velocity, which depends on $\rho$, and 
Table 2. List of variables

\begin{tabular}{|c|c|c|}
\hline Variable & Description & SI units and values of constants \\
\hline$f_{\mathrm{c}}$ & Center frequency of the pRES system & $305 \mathrm{MHz}$ \\
\hline$T_{\mathrm{m}}, T$ & Modeled two-way travel time, two-way travel time & $\mathrm{s}$ \\
\hline$c$ & Speed of light & $2.998 \times 10^{8} \mathrm{~m} \mathrm{~s}^{-1}$ \\
\hline$n, n_{\mathrm{s}}$ & Refractive index, refractive index at the surface & \\
\hline$n_{\mathrm{i}}$ & Refractive index of ice & 1.78 \\
\hline$\rho, \rho_{\mathrm{i}}, \rho_{\mathrm{s}}, \rho_{\mathrm{m}}$ & Density, density of ice [Table 1], density at the surface, modeled density & $\mathrm{kg} \mathrm{m}^{-3}$ \\
\hline$\zeta, \zeta_{\mathrm{i}}$ & Depth, ice-equivalent depth & $\mathrm{m}$ \\
\hline$\varphi$ & Relative phase & $\circ$ \\
\hline$\Delta T_{\mathrm{m}}, \Delta T$ & (Modeled) change in two-way travel time & s \\
\hline$w$ & Generic vertical velocity, modeled vertical velocity & $\mathrm{ms}^{-1}$ \\
\hline$w_{c}, w_{c i}$ & Modeled vertical compaction velocity, modeled ice-equivalent vertical compaction velocity & $\mathrm{m} \mathrm{s}^{-1}$ \\
\hline$W, W_{c}, W_{\mathrm{d}}, W_{\mathrm{i}}$ & $\begin{array}{l}\text { pRES-observed vertical velocity, pRES-observed vertical velocity due to compaction, pRES-observed } \\
\text { vertical velocity due to ice dynamics, pRES-observed ice-equivalent vertical velocity }\end{array}$ & $\mathrm{ms}^{-1}$ \\
\hline$\omega, \omega_{\mathrm{s}}, \omega_{\mathrm{i}}, \omega_{\mathrm{i} \mid \mathrm{s}}$ & $\begin{array}{l}\text { Method 2-derived vertical velocity, method-2-derived vertical velocity at the surface, method-2 derived } \\
\text { ice-equivalent vertical velocity, method-2 ice-equivalent surface vertical velocity }\end{array}$ & $\mathrm{ms}^{-1}$ \\
\hline$z$ & Height above bed & $\mathrm{m}$ \\
\hline$k_{\mathrm{c}}$ & Creep coefficient & $\mathrm{m}^{3} \mathrm{~kg}^{-1}$ \\
\hline$k_{\mathrm{g}}$ & Grain-growth coefficient & $1.3 \times 10^{-7} \mathrm{~m}^{2} \mathrm{~s}^{-1}$ \\
\hline$\sigma$ & Overburden pressure & $\mathrm{kg} \mathrm{m}^{-1} \mathrm{~s}^{-2}$ \\
\hline$r, r_{\mathrm{s}}$ & Grain radius, surface grain radius & $\mathrm{m}$ \\
\hline$R$ & Universal gas constant & $8.31 \mathrm{~J} \mathrm{~K}^{-1} \mathrm{~mol}^{-1}$ \\
\hline$\theta$ & Temperature & $\mathrm{K}$ \\
\hline$\kappa$ & Thermal conductivity & $W \mathrm{~m}^{-1} \mathrm{~K}^{-1}$ \\
\hline$c_{p}$ & Heat capacity & $2009 \mathrm{~J} \mathrm{~kg}^{-1} \mathrm{~K}^{-1}$ \\
\hline$g$ & Gravitational constant & $9.81 \mathrm{~m} \mathrm{~s}^{-2}$ \\
\hline$\dot{b}$ & Accumulation rate & $\mathrm{m} \mathrm{s}^{-1}$ \\
\hline$L$ & Density decay length & $\mathrm{m}$ \\
\hline$\tau$ & Time elapsed between measurements & $\mathrm{s}$ \\
\hline$\dot{\epsilon}_{x}$ & Horizontal strain rate & $s^{-1}$ \\
\hline
\end{tabular}

minimizing the least-squares difference between this optimized velocity, $\omega$, and pRES observations converted into velocities, which also depends on $\rho$. It is convenient to follow Kingslake and others (2016) in defining the ice-equivalent velocity (units of meters ice equivalent, or $\mathrm{m}$ i.e.), which depends only on the pRES measurements and is independent of density, as:

$$
W_{\mathrm{i}}=W \frac{n}{n_{\mathrm{i}}}=\frac{c}{n_{\mathrm{i}}} \frac{\Delta T}{\Delta \tau} .
$$

We assume vertically uniform horizontal strain rates in the top two-thirds of the ice due to ice flow (as in Method 1) and that $\partial \rho / \partial x$ is negligible locally. Conservation of mass under these conditions gives

$$
\rho(\zeta) \dot{\epsilon}_{x}-\frac{\partial}{\partial \zeta} \rho(\zeta) \omega(\zeta)=0
$$

The density profile is approximated by an exponential function:

$$
\rho(\zeta)=\rho_{\mathrm{i}}-\left(\rho_{\mathrm{i}}-\rho_{\mathrm{s}}\right) \exp \left(-\frac{\zeta}{L}\right)
$$

where $\rho_{\mathrm{s}}$ is the surface density and $L$ is the decay length.

Substituting Eqn (7) into Eqn (6) and integrating vertically yields:

$$
\rho \omega=\rho_{\mathrm{s}} \omega_{\mathrm{s}}+\dot{\epsilon}_{x}\left(\rho_{\mathrm{i}} \zeta-L\left[\rho_{\mathrm{i}}-\rho_{\mathrm{s}}\right]\left[1-\mathrm{e}^{-(\zeta / L)}\right]\right),
$$

where $\omega_{\mathrm{s}}$ is the vertical velocity at the surface. To relate $\omega$ to the pRES observations we apply the definition of ice-equivalent velocity (Eqn (5)) to define an ice-equivalent velocity $\omega_{\mathrm{i}}$ and a corresponding surface velocity $\omega_{\mathrm{i} \mid \mathrm{s}}$ as

$$
\omega_{\mathrm{i}}=\omega \frac{n}{n_{\mathrm{i}}}
$$

$$
\omega_{\mathrm{i} \mid \mathrm{s}}=\omega_{\mathrm{s}} \frac{n_{\mathrm{s}}}{n_{\mathrm{i}}}
$$

Substituting $\omega_{\mathrm{i}}$ and $\omega_{\mathrm{i} \mid \mathrm{s}}$ into Eqn (8) and rearranging gives

$$
\omega_{\mathrm{i}}=\frac{n\left(\zeta, \rho_{\mathrm{s}}, L\right)}{\rho\left(\zeta, \rho_{\mathrm{s}}, L\right)}\left(\frac{\rho_{\mathrm{s}}}{n_{\mathrm{s}}} \omega_{\mathrm{i} \mid \mathrm{s}}+\frac{\rho_{\mathrm{i}}}{n_{\mathrm{i}}} \dot{\epsilon}_{x}\left[\zeta-L\left(1-\frac{\rho_{\mathrm{s}}}{\rho_{\mathrm{i}}}\right)\left(1-\mathrm{e}^{-(\zeta / L)}\right)\right]\right) .
$$

Equation (10) shows that the total vertical velocity equals the vertical velocity at the surface plus the second term on the right, which represents the cumulative effect of horizontal strain (the first term in square brackets) and increasing density (the second term in square brackets) on vertical velocity. This term is zero at the surface and, because it is negative, acts to reduce the magnitude of $\omega_{\mathrm{i}}$ from its surface value by an amount that increases with depth and density (note that lowering $L$ and increasing $\rho_{\mathrm{s}}$ increases this term and the density). It increases with depth because the impact of the strain rate accumulates over the ice column. It increases with density because, due to mass conservation, the impact of a given horizontal strain rate on vertical velocity increases with $\rho$.

As in Method 1, we estimate $\dot{\epsilon}_{x}$ as the slope of a linear least-squares fit to $\omega_{\mathrm{i}}(\zeta)$ so that Eqn (10) contains three unknown parameters: $\rho_{\mathrm{s}}, \omega_{\mathrm{i} \mid \mathrm{s}}$ and $L$. Using MATLAB's fminsearch we minimize the square of the difference between the pRES-measured $W_{\mathrm{i}}$ (Eqn (5)) and $\omega_{\mathrm{i}}($ Eqn (10)) to estimate optimal values for the three unknowns:

$$
\min \int_{\zeta_{\mathrm{b}}}^{0}\left|W_{\mathrm{i}}-\omega_{\mathrm{i}}\left(\zeta, L, \rho_{\mathrm{s}}, \omega_{\mathrm{i} \mid \mathrm{s}}\right)\right|^{2} \mathrm{~d} \zeta,
$$

where $\zeta_{b}$ is the lower bound of the region where the horizontal strain rate is considered constant. With these parameters, we compute the density profile using Eqn (7). Finally, the density profile is used to convert $T$ and $\Delta T$ into $\zeta$ and $W$ using Eqns (1) and (4), respectively. 
As in Method 1, the firn compaction velocity $W_{\mathrm{c}}$ is extracted by subtracting the ice-dynamic contribution, $W_{\mathrm{d}}$, from $W$.

\subsection{Estimating accumulation rates from pRES data}

The average accumulation rate, $\dot{b}$, is a useful environmental indicator, and serves as a boundary condition in the physics-based compaction model (Section 2.5). As an alternative to ice-core measurements or regional climate models, we can use pRES measurements to estimate $\dot{b}$. If we assume that ice-sheet thickness is in steady state at our field sites, $\dot{b}$ equals the ice-equivalent vertical velocity at the surface: ignoring ablation, the accumulation must balance downward advection for the surface height to remain constant. To calculate the vertical velocity at the surface, we used a linear least-squares fit to the middle third of pRES-derived profiles to find $W_{\mathrm{i}}(\zeta)$ (see Section 2.3.1 for the depth ranges used), then extrapolated this linear fit to the surface to estimate the surface ice-equivalent vertical velocity. We compared these estimates to ice-core measurements and 40-year mean accumulation rates simulated using RACMO2.3p2 (Section 2.1, Table 1). As a boundary condition on the firn compaction model described in the next section, we used these pRES-derived accumulation rates at all KIR sites and all but one SIR site, and core-derived accumulation rates at FP and the SIR pRES site closest to the core (site 18).

\subsection{Firn compaction model}

\subsubsection{Equations}

Our model closely follows the model proposed by Arthern and others (2010) (their Appendix B), except that we take a Eulerian approach instead of a Lagrangian one. We define a 1-D Eulerian coordinate system where the vertical coordinate $z$ is positive upward and the vertical velocity $w$ is positive downward. We use $\rho_{\mathrm{m}}$ to denote a 'modeled density' to distinguish it from other densities defined earlier. As all deformation in this model is due to firn compaction, $w$ is related to density through mass conservation:

$$
\frac{\partial w}{\partial z}=\rho_{\mathrm{m}}^{-1} \frac{D \rho_{\mathrm{m}}}{D t},
$$

where $D / D t$ is the material derivative $(=\partial / \partial t-w \partial / \partial z)$. Integrating upward from the firn-ice transition, $z_{\mathrm{t}}$, gives

$$
w-w_{\mathrm{t}}=\int_{z_{\mathrm{t}}}^{z} \frac{1}{\rho_{\mathrm{m}}} \frac{D \rho_{\mathrm{m}}}{D t} d z
$$

where $w_{\mathrm{t}}$ is the velocity at the base of the firn pack that we impose (Section 2.5.2). Following Arthern and others (2010), we describe firn densification as a function of overburden pressure, $\sigma$, temperature, $\theta$, grain radius, $r$ and density, $\rho_{\mathrm{m}}$, as follows:

$$
\frac{D \rho_{\mathrm{m}}}{D t}=k_{\mathrm{c}} \sigma r^{-2}\left(\rho_{\mathrm{i}}-\rho_{\mathrm{m}}\right) \exp \left(-\frac{E_{\mathrm{c}}}{R \theta}\right)
$$

where $R$ is the universal gas constant $\left(8.31 \mathrm{~J} \mathrm{~K}^{-1} \mathrm{~mol}^{-1}\right), E_{\mathrm{c}}$ is the activation energy for diffusion creep and is found by minimizing the mismatch between the modeled and observed velocities or densities (Section 2.6), and $k_{\mathrm{c}}$ is a constant that depends on the density regime:

$$
k_{\mathrm{c}}=\left\{\begin{array}{l}
9.2 \times 10^{-9} \mathrm{~m}^{3} \mathrm{~kg}^{-1} \text { where } \rho_{\mathrm{m}}<550 \mathrm{~kg} \mathrm{~m}^{-3} \\
3.7 \times 10^{-9} \mathrm{~m}^{3} \mathrm{~kg}^{-1} \text { where } \rho_{\mathrm{m}} \geq 550 \mathrm{~kg} \mathrm{~m}^{-3}
\end{array}\right.
$$

To track $\rho_{\mathrm{m}}$ on the Eulerian grid, we expand the left side of Eqn (14) using the definition of the material derivative to give

$$
\frac{\partial \rho_{\mathrm{m}}}{\partial t}=k_{\mathrm{c}} \sigma r^{-2}\left(\rho_{\mathrm{i}}-\rho_{\mathrm{m}}\right) \exp \left(-\frac{E_{\mathrm{c}}}{R \theta}\right)+w \frac{\partial \rho_{\mathrm{m}}}{\partial z} .
$$

Defining $\sigma=0$ at the surface,

$$
\sigma=g \int_{z}^{z_{\mathrm{s}}} \rho(z) d z
$$

where $g$ is the gravitational constant $\left(9.81 \mathrm{~m} \mathrm{~s}^{-2}\right)$. Temperature, $\theta$, evolves as

$$
\frac{\partial \theta}{\partial t}=\frac{1}{\rho_{\mathrm{m}} c_{\mathrm{p}}} \frac{\partial}{\partial \mathrm{z}} \kappa(\rho) \frac{\partial \theta}{\partial \mathrm{z}}+w \frac{\partial \theta}{\partial z},
$$

where the heat capacity $c_{p}=2009 \mathrm{~J} \mathrm{~kg}^{-1} \mathrm{~K}^{-1}$ (Paterson, 1994) and the thermal conductivity $\kappa$ depends on the local density as $\kappa\left(\rho_{\mathrm{m}}\right)$ $=2.1\left(\rho_{\mathrm{m}} / \rho_{\mathrm{i}}\right)^{2} \mathrm{~W} \mathrm{~m}^{-1} \mathrm{~K}^{-1}$ (Arthern and Wingham, 1998). The square of the grain radius increases with time according to an Arrhenius temperature dependence and is advected with flow:

$$
\frac{\partial r^{2}}{\partial t}=k_{\mathrm{g}} \exp \left(-\frac{E_{\mathrm{g}}}{R \theta}\right)+w \frac{\partial r^{2}}{\partial z}
$$

where $E_{\mathrm{g}}$ is the activation energy for volume self-diffusion and is found by minimizing the mismatch between the modeled and observed velocities or densities (Section 2.6), and $k_{\mathrm{g}}$ is the graingrowth coefficient, $1.3 \times 10^{-7} \mathrm{~m}^{2} \mathrm{~s}^{-1}$ (Arthern and others, 2010). Note that grain growth is independent of overburden pressure.

\subsubsection{Boundary conditions}

To conserve mass globally and allow a steady state to be reached, we impose a lower boundary condition $w\left(z_{\mathrm{t}}\right)=\dot{b}$, where $\dot{b}$ is the ice-equivalent accumulation rate found in Section 2.4 at all locations except those nearest to the FP and ST ice cores, where icecore-measured rates are used instead (Table 1, personal communication from R. Mulvaney, 2021). For temperature boundary conditions (Eqn (18)) we used the mean annual surface temperatures listed in Table 1 at the model's upper boundary and at the model's lower boundary we used the temperature gradient measured at FP at the depth where $\rho=900 \mathrm{~kg} \mathrm{~m}^{-3}, \partial \theta / \partial z=0.0034 \mathrm{~K} \mathrm{~m}^{-1}$. Following Arthern and others (2010), we used a surface grain radius of $r_{\mathrm{s}}^{2}=10^{-9} \mathrm{~m}$. As no field measurements of surface density were available, we estimated $\rho_{\mathrm{s}}$ by extrapolating the density profiles at FP and SIR using a widely used logarithmic function of depth (Herron and Langway, 1980; their Eqns (7 and 10)) in the upper tens of meters. At FP $\rho_{\mathrm{s}}=435 \mathrm{~kg} \mathrm{~m}^{-3}$ and at $\operatorname{SIR} \rho_{\mathrm{s}}=$ $400 \mathrm{~kg} \mathrm{~m}^{-3}$. This approach likely overestimates the true surface density, as very-near-surface densification processes are not represented by the model of Herron and Langway (1980). However, it provides a reasonable boundary condition in the absence of direct field observations. The temperature boundary conditions, $\dot{b}, \rho_{\text {s }}$ and $r_{s}^{2}$ were held constant throughout all simulations.

\subsubsection{Thickness evolution, numerical implementation and initial} conditions

We solved the model equations numerically on a Eulerian grid with an initial thickness $h=250 \mathrm{~m}$. For each time step, the grid was allowed to thin or thicken according to $\mathrm{d} h / \mathrm{d} t=\dot{b}\left(\rho_{\mathrm{i}} / \rho_{\mathrm{s}}\right)-w_{\mathrm{s}}$, where $w_{\mathrm{s}}$ is the velocity at the surface, and the gridpoints were repositioned (ensuring a grid spacing of $\sim 0.33 \mathrm{~m}$ ); all variables were interpolated onto the new grid. We used a time step of 0.001 years $(\sim 9 \mathrm{~h})$. Density was initialized 

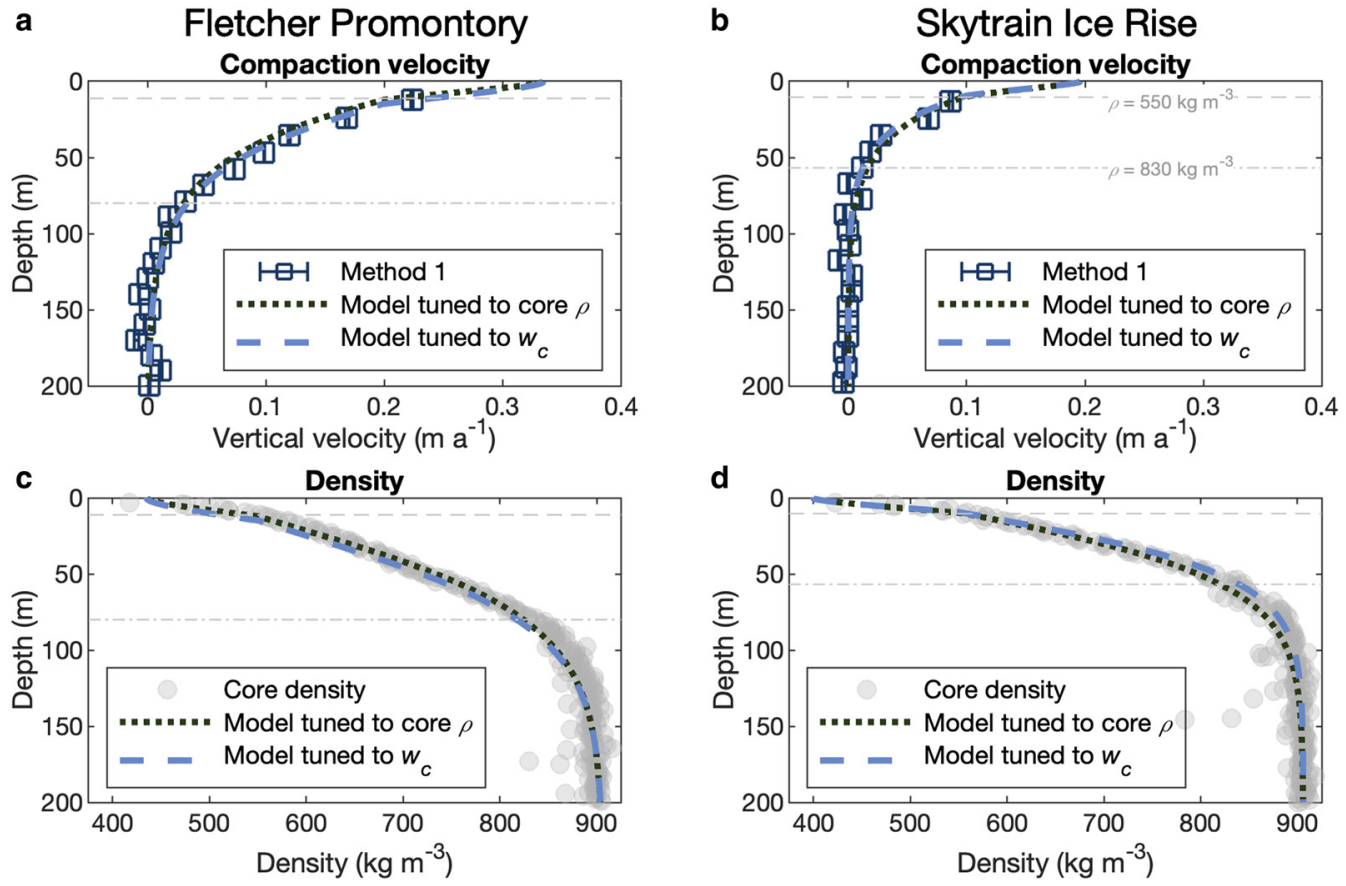

Fig. 2. Core observations, modeled velocity and densities, and Method 1 compaction velocities. Left panels are from FP, the right panels are from SIR, top panels are compaction velocities and bottom panels are densities. In the top panels (a,b), blue squares are compaction velocities derived from pRES measurements using Method 1. Uncertainties are derived by taking into account the signal-to-noise ratio of each englacial reflector used to computed vertical velocities (Section 2.2) and are represented by the width of the bar symbols. Gray circles in the bottom panels are ice core-measured densities. The dashed and dotted curves show the model output (Section 2.5), where the dashed blue lines are generated from a model tuned to pRES vertical velocities, and the dotted black lines are generated from a model tuned to core densities. The gray horizontal dashed and dot-dashed lines show where core-derived densities are 550 and $830 \mathrm{~kg} \mathrm{~m}^{-3}$, respectively, corresponding to the compaction transition density identified by Herron and Langway (1980) and the lock-in density.

with an exponential profile (Eqn (7)) with $L=40 \mathrm{~m}$ (note that in Method 2 above $L$ was treated as an unknown). The initial temperature profile linearly increased with depth at a rate of $0.0034 \mathrm{~K} \mathrm{~m}^{-1}$ (the gradient measured in the FP borehole). Velocity was calculated every time step using Eqn (13) and the values of $\sigma, \rho_{\mathrm{m}}, \theta$ and $r^{2}$ from the previous time step. Density, grain size and temperature were updated from the previous time step using Eqns (16-19). Simulations terminated when $\partial \rho_{m} / \partial t<10^{-6} \mathrm{~kg} \mathrm{~m}^{-3} \mathrm{~s}^{-1}$, approximating a steady state.

\subsection{Using densification rates to tune models}

A common procedure in firn modeling is to tune model parameters to observations of density (e.g. Herron and Langway, 1980) or compaction (Arthern and others, 2010; Morris, 2018). We investigate how the optimal values of the grain growth and compaction activation energies, $E_{\mathrm{g}}$ and $E_{\mathrm{c}}$, of the model (Section 2.5), depend on whether we optimize using compaction velocities (estimated with pRES) or density profiles (measured in the two ice cores). All optimization was performed in MATLAB using fminsearch to minimize the least-squares difference between modeled and measured densities and compaction velocities, where modeled values were first interpolated to the depths of pRES measurements or density measurements for comparison.

\subsection{Comparing models with pRES observations}

Finally, we introduce a method for comparing model output to radar observations. This approach converts modeled depth and compaction velocities into two-way travel time, $T_{\mathrm{m}}$ (to denote 'modeled two-way travel time') and relative change in two-way travel time, $\Delta T_{\mathrm{m}}$, so that they can be directly compared to the respective pRES measurements. Here, we use the model presented in
Section 2.5, although any compaction model could be used. As a reminder, $W$ denotes pRES-derived velocities (Eqn (4)) and $w_{\mathrm{c}}$ denotes modeled compaction velocities (Section 2.5). Compaction velocities are modeled as described in Section 2.5, where activation energies are tuned to the pRES measurements at FP, and to sites 18 and 5 for the transects across SIR and KIR, respectively. Modeled compaction velocity, $w_{\mathrm{c}}$, is converted into an ice-equivalent velocity $w_{\mathrm{ci}}$ using Eqn (5). We then add the component of vertical velocity due to the horizontal strain rate, $W_{\mathrm{d}}$ (estimated using a linear fit to the pRES-derived ice-equivalent velocity, $W_{\mathrm{i}}$ ) to $w_{\mathrm{ci}}$ to estimate a modeled, ice-equivalent, total vertical velocity, $w_{\mathrm{i}}=w_{\mathrm{ci}}+W_{\mathrm{d}}$. Then $w_{\mathrm{i}}$ and the depth of each modeled gridpoint is converted into $\Delta T_{\mathrm{m}}$ and $T_{\mathrm{m}}$, respectively, using the modeled density profile $\left(\rho_{\mathrm{m}}\right)$, as follows:

$$
\begin{gathered}
\Delta T_{\mathrm{m}}=w_{\mathrm{i}}(\zeta) \Delta \tau \frac{n\left(\rho_{\mathrm{m}}(\zeta)\right)}{c} \\
T_{\mathrm{m}}=\frac{2}{c} \int_{0}^{\zeta} n\left(\rho_{\mathrm{m}}\right) d \zeta .
\end{gathered}
$$

These modeled values can then be directly compared to quantities observed by pRES, $\Delta T$ and $T$.

\section{Results}

\subsection{Compaction velocities and density profiles}

At all sites, compaction velocities are fastest at the surface (or as close to the surface as possible, given the constraints of the pRES system) and decrease with depth until they approach zero at the bottom of the firn-ice transition zone. 

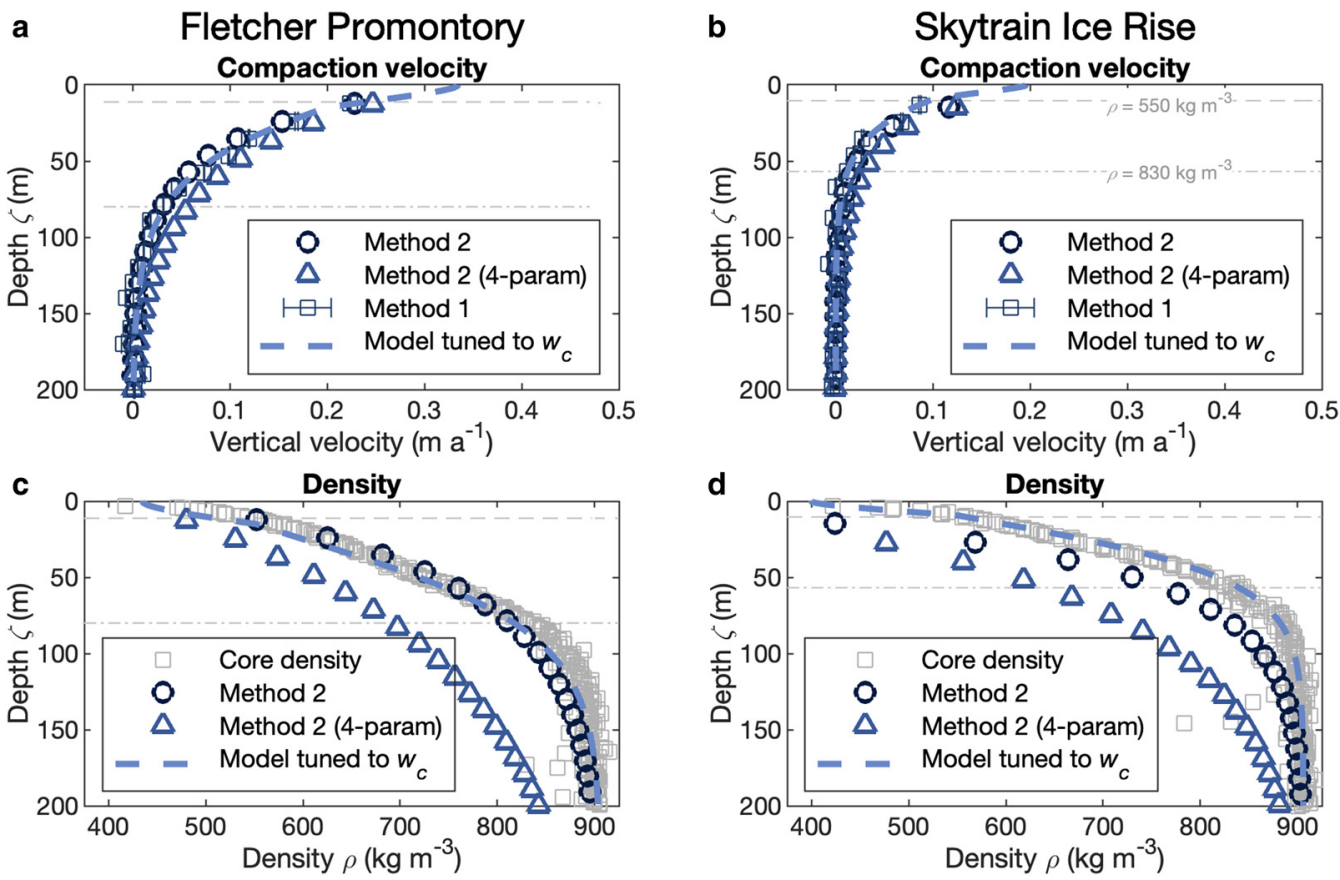

Fig. 3. Inverted compaction velocities and densities from Method 2 at FP and SIR. Method 2 inverts for a density profile and velocity given pRES measurements of the ice-equivalent vertical velocity. In (a) and (b), Method 2 compaction velocities in blue circles are compared to compaction velocities from Method 1 (blue squares) and the model (blue dashed line; Section 2.5) at FP and SIR. At FP, Method 2, the model and Method 1 agree at all depths within $0.02 \mathrm{~m} \mathrm{a}^{-1}$. The fourparameter inversion (triangles), described in the discussion, overestimates the firn compaction velocity between $\zeta=25 \mathrm{~m}$ and the firn-ice transition. At SIR, Method 2 agrees with Method 1 velocities to within $0.01 \mathrm{~m} \mathrm{a}^{-1}$ below $\zeta=20 \mathrm{~m}$, while the four-parameter inversion overestimates the compaction velocity by $0.02-0.03 \mathrm{~m} \mathrm{a}^{-1}$. In (c) and (d), densities of Method 2 are compared to core observations (gray squares) and the pRES-tuned model densities (dashed blue lines). At FP, Method 2 agrees with the density profile until $800 \mathrm{~kg} \mathrm{~m}^{-3}$ below which it underestimates the density. The four-parameter inversion underestimates the density by $50-150 \mathrm{~kg}$ $\mathrm{m}^{-3}$. At SIR, Method 2 and four-parameter inversions underestimate density by $50-100$ and $100-200 \mathrm{~kg} \mathrm{~m}^{-3}$ respectively. The gray horizontal dashed and dotdashed lines show where core-derived densities are 550 and $830 \mathrm{~kg} \mathrm{~m}^{-3}$, respectively.

Figures 2a, c show compaction velocities from FP estimated from pRES measurements using Method 1 (Section 2.3.1) and densities measured in the FP core. The pRES-estimated compaction velocity is $0.22 \mathrm{~m} \mathrm{a}^{-1}$ at $12 \mathrm{~m}$ depth, just below the first density transition zone of $550 \mathrm{~kg} \mathrm{~m}^{-3}$. The firn reaches the pore close-off density $\left(830 \mathrm{~kg} \mathrm{~m}^{-3}\right)$ at $79 \mathrm{~m}$ (Mulvaney and others, 2014); compaction can be seen until $\sim 130 \mathrm{~m}$, below which velocities approach zero, with fluctuations of $0.01 \mathrm{~m} \mathrm{a}^{-1}$ or less.

Figures $2 \mathrm{~b}, \mathrm{~d}$ show Method 1 compaction velocities from site 18 on SIR (the pRES measurement closest to the SIR core), and densities measured from the SIR core. Compaction velocities are slower than that at FP, likely due to lower accumulation rates (Table 1). The pRES-estimated compaction velocity is $0.09 \mathrm{~m} \mathrm{a}^{-1}$ at $13 \mathrm{~m}$ depth, just below the first density transition zone of $550 \mathrm{~kg} \mathrm{~m}^{-3}$. The firn reaches the pore close-off density at $56 \mathrm{~m}$ (personal communication from R. Mulvaney, 2021); compaction can be seen until $\sim 85 \mathrm{~m}$. Like at FP, below this depth velocities approach zero, with fluctuations of $0.01 \mathrm{~m} \mathrm{a}^{-1}$ or less.

Method 2 employs a simple inversion to simultaneously estimate vertical profiles of density and compaction velocity. It is useful for locations without independent density measurements. We apply it to the ice-core adjacent pRES measurements at FP and site 18 on SIR to assess the methodology (Fig. 3), and then across the KIR and SIR transects, which have no density measurements (Fig. 4).

Figure 3 compares the results of Method 2 (Section 2.3.2) to the results of Method 1 (Section 2.3.1) and the pRES-tuned model (Section 2.5). Figure 3a shows that at FP, compaction velocities from Method 2, Method 1 and the model agree to within $0.02 \mathrm{~m} \mathrm{a}^{-1}$. Figure $3 \mathrm{c}$ shows that the density estimated with Method 2 largely agrees with the observed density, until $\sim 800$ $\mathrm{kg} \mathrm{m}^{-3}$, reaching ice density $20-30 \mathrm{~m}$ deeper than the core densities, while staying within $25 \mathrm{~kg} \mathrm{~m}^{-3}$ of the observations.
In Fig. 3b, Method 2 compaction velocities at SIR site 18 match those computed with Method 1 to within $0.025 \mathrm{~m} \mathrm{a}^{-1}$ in the region above $20 \mathrm{~m}$ depth and within $0.01 \mathrm{~m} \mathrm{a}^{-1}$ in the region below. Method 2 compaction velocities decay to zero near $100 \mathrm{~m}$ depth, $\sim 20 \mathrm{~m}$ below the Method 1 firn-ice transition. Figure 3d shows that Method 2 results in densities $100-200 \mathrm{~kg} \mathrm{~m}^{-3}$ lower than the observed densities. This is due, in large part, to an underestimation of the surface density and overestimation of $L$ by the minimization.

Figure 4 shows results from applying Method 2 to locations on SIR and KIR. Across KIR in Figure 4a, we see a gradient in total vertical velocities across the divide. After removing the ice dynamic component to obtain firn compaction velocities, this gradient is largely absent (Fig. 4c). Within $25 \mathrm{~m}$ of the surface, firn compaction velocities across KIR vary between 0.05 and $0.17 \mathrm{~m} \mathrm{a}^{-1}$. Despite this variation in near-surface firn velocities, at most locations, the firn-ice transition zone is reached near the same depth, $\sim 150 \mathrm{~m}$, although a few sites show small $\left(<0.01 \mathrm{~m} \mathrm{a}^{-1}\right)$ compaction velocities below this depth.

At SIR (Figs 4b, d), we do not see a gradient across the transect in either total velocities or compaction velocities. Between the surface and $25 \mathrm{~m}$ depth, compaction velocities range from 0.05 to $0.14 \mathrm{~m} \mathrm{a}^{-1}$. At most sites the compaction velocities reach zero above $150 \mathrm{~m}$; however, as at KIR, data at a few sites show compaction much deeper.

\subsection{Estimated accumulation rates}

Figure 5a shows that at SIR, pRES-derived accumulation rates are $0.09-0.11 \mathrm{~m}$ i.e. $\mathrm{a}^{-1}$ near the divide and are systematically larger on the flanks ( $>500 \mathrm{~m}$ from the divide; Figs $1 \mathrm{c}, \mathrm{e}$ ), with the largest accumulation rates of $0.14-0.16 \mathrm{~m}$ i.e. $\mathrm{a}^{-1}$ at the northern end of the transect. In comparison, multi-centennial-averaged accumulation rates measured from the SIR ice core are $0.15 \pm 0.02 \mathrm{~m}$ i.e. $\mathrm{a}^{-1}$ 

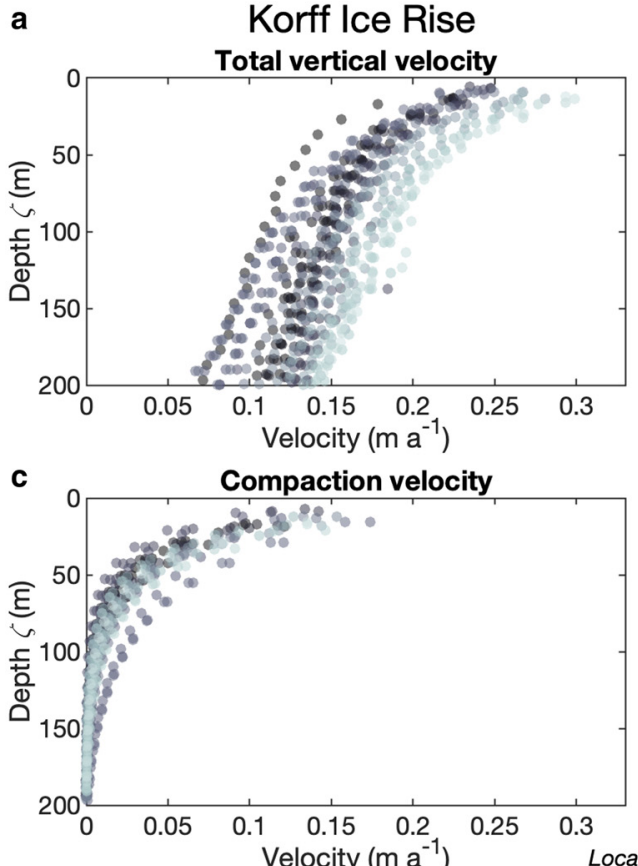
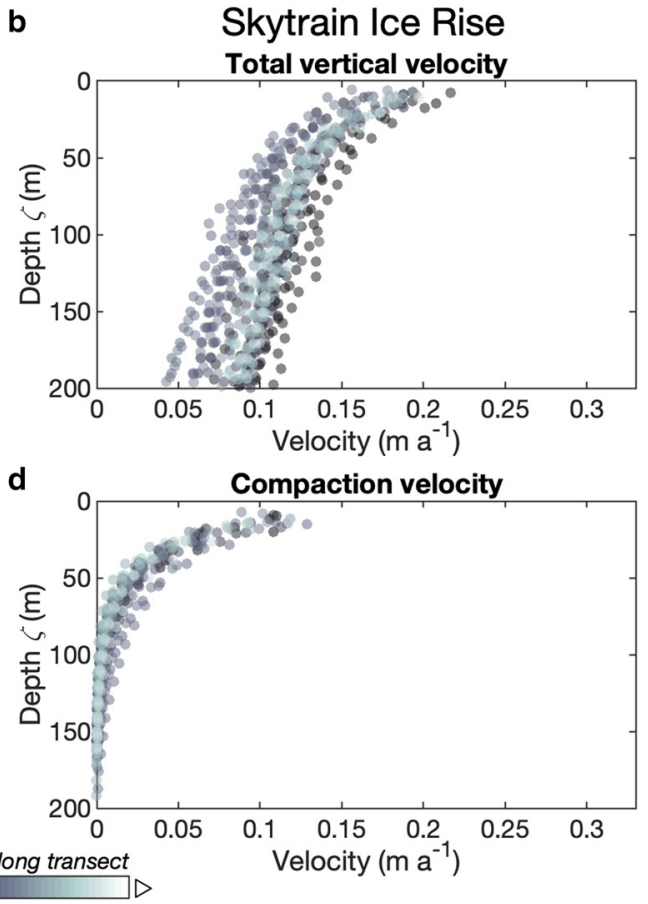

Fig. 4. Spatial variability of total velocities and compaction velocities at SIR and KIR obtained using Method 2. Method 2 can generate compaction velocity profiles at locations where we lack coincident density profiles across two transects, a northeastern-southwestern transect on KIR (black-to-blue gradient, Fig. 1b) and a north-to-south transect on SIR (black-to-blue gradient, Fig. 1c). Panels a and b show the total vertical velocity measured by each of the pRES points along KIR and $\mathrm{SIR}$, respectively. Panels $\mathrm{c}$ and $\mathrm{d}$ show the firn compaction velocity. Note in panel a at KIR, the eastern flank (light blue) generally flows faster than the western flank, but that this trend is not evident in the compaction velocity estimates (c). The triangle to the right of the colorbar indicates the orientation of the transects in Figures $1 b$, c.

(personal communication from R. Mulvaney, 2021). RACMO accumulation rates in the area are slightly higher, at $0.23 \pm 0.05$ m i.e. $\mathrm{a}^{-1}$ (Section 2.1; Table 1).

At KIR, pRES-derived accumulation rates are larger on the northeast side of the divide than on the southwest side. In Figure $5 \mathrm{~b}$, on the southwest side, $1000 \mathrm{~m}$ or more from the ice divide (Figs 1b, d), pRES-derived accumulation rates are 0.13$0.18 \mathrm{~m}$ i.e. $\mathrm{a}^{-1}$. On the northeast side, accumulation rates are $0.20-0.22 \mathrm{~m}$ i.e. $\mathrm{a}^{-1}$. These values are in broad agreement with accumulation rates from RACMO, $0.21 \pm 0.03 \mathrm{~m}$ i.e. $\mathrm{a}^{-1}$.

At FP (not shown in Fig. 5), the pRES-derived accumulation rate is $0.40 \mathrm{~m}$ i.e. $\mathrm{a}^{-1}$, which exceeds the revised $0.30 \mathrm{~m}$ i.e. $\mathrm{a}^{-1}$ multi-centennial-averaged rate measured by Mulvaney and others (personal communication from R. Mulvaney, 2021). Both accumulation estimates are in agreement with accumulation rates from RACMO, $0.38 \pm 0.08 \mathrm{~m}$ i.e. $\mathrm{a}^{-1}$.

\subsection{Modeled firn compaction velocities}

In Figures 2 and 3, Methods 1 and 2 are compared to steady-state compaction velocities modeled with the physics-based model (Section 2.5). Figure 2 plots two model outputs with different activation energies, tuned to minimize the least-squares difference between the model and either the ice-core density measurements or the pRES-derived densification rates. Figure 3 shows model results from the latter.

Figures $2 \mathrm{a}, \mathrm{b}$ show that the model reproduces the Method1-derived vertical compaction rates at both FP and SIR. The bestfit activation energies when tuned to the pRES observations at FP are $E_{\mathrm{c}}=68.7 \mathrm{~kJ}$ and $E_{\mathrm{g}}=50.3 \mathrm{~kJ}$ and at SIR are $E_{\mathrm{c}}=66.8 \mathrm{~kJ}$ and $E_{\mathrm{g}}=49.2 \mathrm{~kJ}$. The best-fit activation energies when tuned to the ice-core densities from FP are $E_{\mathrm{c}}=67.1 \mathrm{~kJ}$ and $E_{\mathrm{g}}=48.6 \mathrm{~kJ}$ and from SIR are $E_{\mathrm{c}}=66.5 \mathrm{~kJ}$ and $E_{\mathrm{g}}=48.5 \mathrm{~kJ}$. The pRES-tuned model reproduces Method 1 compaction velocities at both sites. The density-tuned model tends to underestimate Method 1 velocities by $<0.03 \mathrm{~m} \mathrm{a}^{-1}$ at FP, and agree with Method 1 at SIR.
Figures 2c, d show that at FP and SIR we find close agreement between modeled and measured densities, especially above the lock-in depth $\left(\rho=830-850 \mathrm{~kg} \mathrm{~m}^{-3}\right)$. At FP, the pRES-tuned model predicts slightly lower densities than measured (by $<30 \mathrm{~kg} \mathrm{~m}^{-3}$ ) at depths between the surface and $45 \mathrm{~m}\left(\rho<700 \mathrm{~kg} \mathrm{~m}^{-3}\right)$. Between $45 \mathrm{~m}$ and the lock-in depth (where $\rho=830 \mathrm{~kg} \mathrm{~m}^{-3}$ ), both models agree within $10 \mathrm{~kg} \mathrm{~m}^{-3}$ to each other and the core; below the lock-in depth, the models show lower densities, achieving ice density $20 \mathrm{~m}$ below the ice core.

At SIR, both the pRES- and core-tuned models agree with the measured densities within $<5 \mathrm{~kg} \mathrm{~m}^{-3}$ between the surface and 15 $\mathrm{m}$. Below $15 \mathrm{~m}$, the pRES-tuned model overestimates the density by $<20 \mathrm{~kg} \mathrm{~m}^{-3}$ until the firn-ice transition, and reaches ice density at about the same depth as the ice core. The core-tuned model gives slightly lower densities than observations below the lock-in depth, and reaches the firn-ice transition $\sim 15 \mathrm{~m}$ below the observations.

\subsection{Modeled pRES observations}

Finally, the method described in Section 2.7 compares two-way travel times and change in two-way travel times derived from the physics-based model to pRES measurements. Figure 6 shows that two-way travel times are on the order of microseconds (panels a, c, e), changes in two-way travel time are on the order of nanoseconds (panels a, c, e), and the model results agree with pRES observations to within 5-20\%.

For FP, Figs $6 \mathrm{a}$, b show that the modeled two-way travel times are within $10 \%$ of the measured values throughout the profile except for $T_{\mathrm{m}}<0.5 \mathrm{~ms}$, where the change in two-way travel time is overestimated by the model.

At SIR, Figs $6 \mathrm{c}$, d show that the model largely agrees with the observations, with a tendency to underestimate the change in twoway travel time in the near surface; the model mostly reproduces $\Delta T$ within $15 \%$ of pRES observations. 

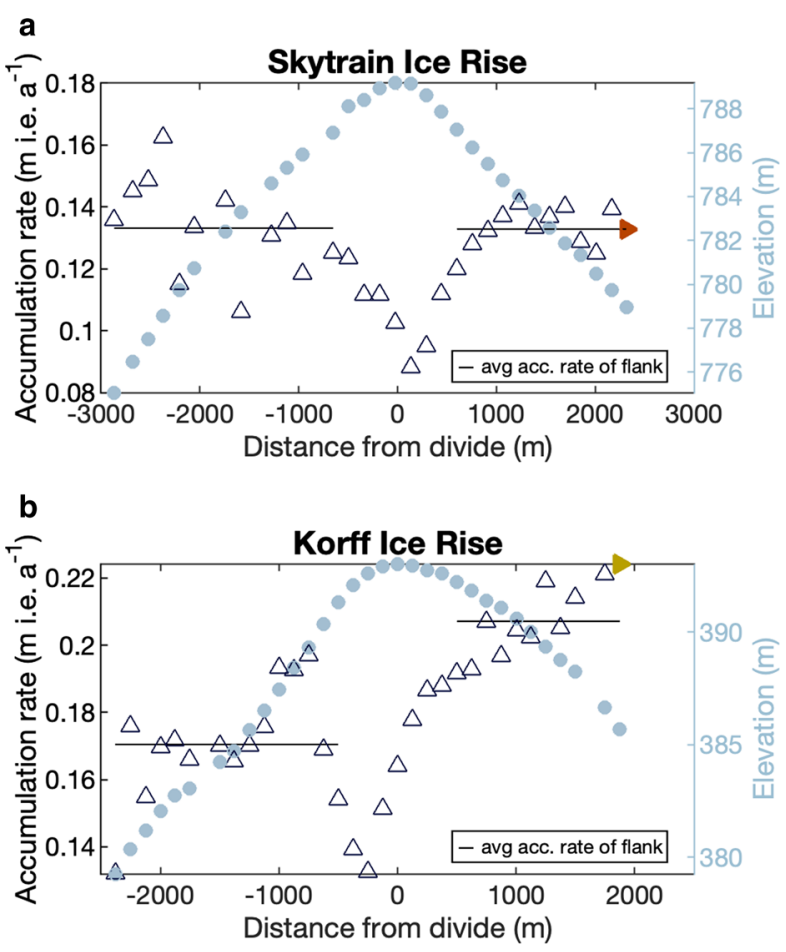

Fig. 5. pRES-derived accumulation rates at SIR and KIR. Accumulation rates (blue triangles) are derived using the steady-state assumption described in Section 2.4. Solid lines show the average accumulation rate of each flank using points $>500 \mathrm{~m}$ from the divide. The average accumulation rates at SIR (a) are the same on both flanks, while at KIR (b), the northeast flank (right side of plot) has on average $0.04 \mathrm{~m}$ i.e. $\mathrm{a}^{-1}$ higher accumulation than the southwest flank (left side of plot). The filled triangles orient the transects with respect to Figure 1 . The light blue circles show the elevation change and topography of the transect as interpolated from REMA.

At KIR, Figs 6e, $\mathrm{f}$ show that the model slightly underestimates the change in two-way travel time; the model reproduces $\Delta T$ within $15 \%$ of pRES observations at most sites, and within $20 \%$ at the rest. Although not depicted in Fig. 6, both the model and the pRES observations indicate an accumulation gradient across the divide, where the southwest flank, with lower accumulation rates, has smaller changes in two-way travel time, and the northeast flank, with higher accumulation rates, has larger changes in two-way travel time.

\section{Discussion}

We have shown that we can measure firn densification with a ground-based phase-sensitive radar. We have presented two methods to isolate firn compaction velocities from pRES observations of vertical velocity using simple assumptions about horizontal ice flow and/or density. Method 1 uses an independently measured density to convert the relative change in two-way travel time into a profile of vertical velocity, then isolates the firn compaction component by removing the contribution of horizontal strain rate due to ice flow from the total velocity (Section 2.3.1). The compaction velocities extracted using this method closely match velocities simulated by a modified version of the physics-based compaction model described by Arthern and others (2010). Method 2 extracts firn compaction velocities in cases where we lack coincident density measurements. Using conservation of mass and an exponential expression to describe density, this simple inverse method produced compaction rates that broadly agree with the results of Method 1 and modeled compaction rates, even in the presence of the erroneous vertical variations in pRES-derived velocities seen at some SIR locations (these are discussed more below).

We also detail a method for extracting accumulation rates from the pRES observations at locations where a steady state can be assumed. We compare these to rates measured in ice cores and modeled using RACMO2.3p2. Modeled accumulation rates agree within uncertainty bounds to pRES-derived rates, except at SIR where the model estimate exceeded both the pRES-derived values and the ice core-measured values. At KIR this agreement and the steady-state assumption were consistent with the results of Kingslake and others (2016), which indicated steady ice thickness on the centennial to millennial timescale. The spatial variability exhibited by the pRES-derived accumulation estimates need to be verified against independent highresolution accumulation estimates (e.g. from shallow radar profiling or shallow cores); however, our results indicate that accumulation may increase southwest to northeast across the ice divide on $\mathrm{KIR}$, which is consistent with the asymmetry in KIR's deep isochrones noted by Kingslake and others (2016).

Using pRES to measure firn compaction has some advantages over previous methods. pRES is a lightweight, surface-based system that can be deployed by a single person, allowing many more point measurements to be made in a single field campaign than with, for example, borehole instrumentation. Moreover, pRES can measure vertical velocities from the near surface through to near the glacier bed, whereas firn-compaction measurements from borehole instrumentation (Arthern and others, 2010) and airborne radar (Medley and others, 2015) have been restricted to the upper tens of meters by instrument design and radio-wave penetration, respectively. Measuring full-depth velocity profiles is useful because it allows us to estimate and remove the contribution of horizontal strain rates in the firn. Some previous research has ignored this component of strain in the firn pack (Arthern and others, 2010), while others have accounted for it using surface velocity fields (e.g. Morris and others, 2017). An advantage of our approach is that we estimate the contribution of horizontal strain rates locally, and so it can be applied in slowmoving locations such as ice rises where ice cores are often drilled, but satellite-based surface velocities are unreliable. Removing the contribution of horizontal strain rate is perhaps more important in our study than in previous research because pRES measures compaction rates in the lower part of the firn pack, where the horizontal strain rates make up a higher proportion of the total strain than in the upper tens of meters. Finally, another advantage of our approach is that it can easily be applied to data collected using the successor to pRES, autonomous pRES (ApRES, Nicholls and others, 2015). Due to its robust design and low power requirements, ApRES can operate autonomously for long periods, collecting near-continuous strain rate measurements. Future research using our methods could deploy ApRES to monitor seasonal or interannual variability in firn compaction.

Limitations of our methods are associated with which stresses contribute to compaction, the vertical variation of horizontal strain rates and density (particularly through their impact on the optimal parameters found in Method 2), a lack of near-surface radar returns, and the model we compare to our results. We discuss these in order below.

Following previous work (e.g., Jenkins and others, 2006), we assume that only hydrostatic stresses contribute to firn compaction in both the firn model and pRES-derived vertical strain rates. In the model, this leads to a simplified firn constitutive equation, Eqn (14). In the pRES data analysis, this assumption allows us to isolate strain rates associated with firn compaction from those associated with horizontal ice flow by assuming they are additive and separable. This approach is consistent Jenkins and others (2006), who showed that at least in simple flow regimes, firn densification and ice-dynamic contributions to vertical velocity are independent. In more complicated flow regimes this may not be valid. For example, in shear margins, strain softening has been hypothesized to enhance firn compaction, 
Fletcher Promontory
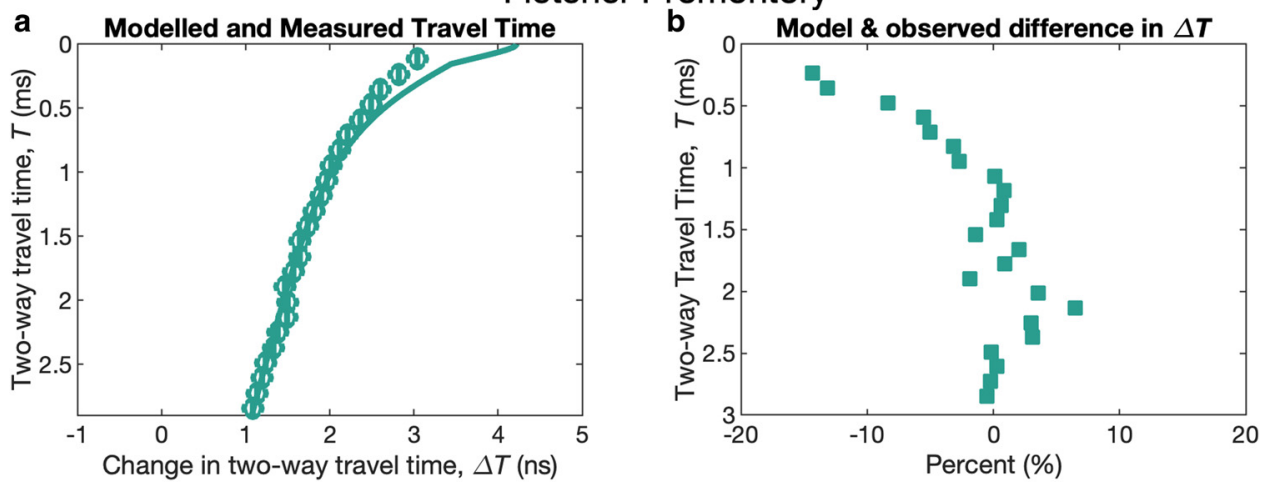

Skytrain Ice Rise
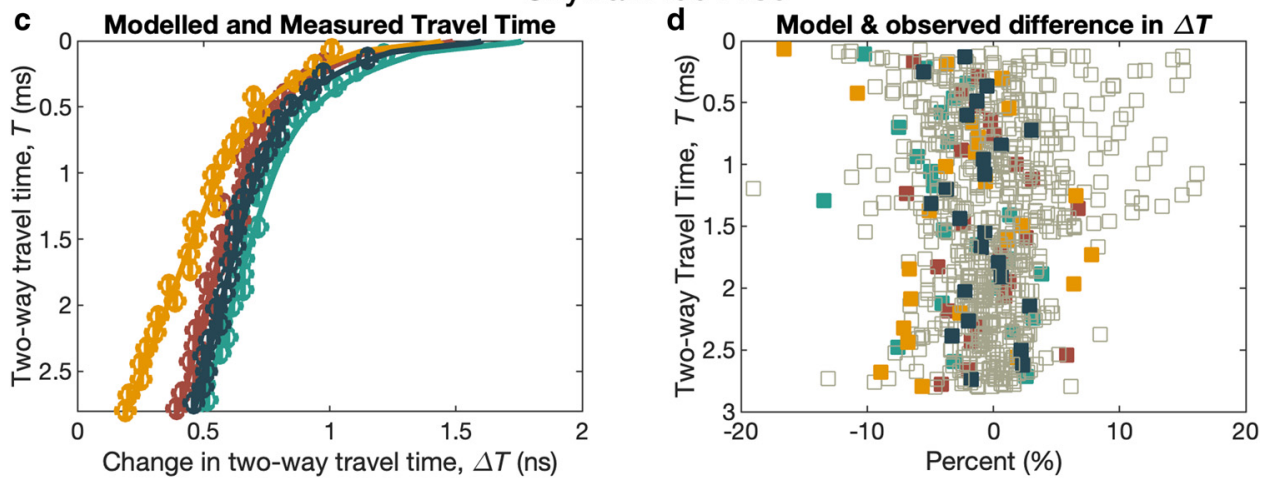

Korff Ice Rise
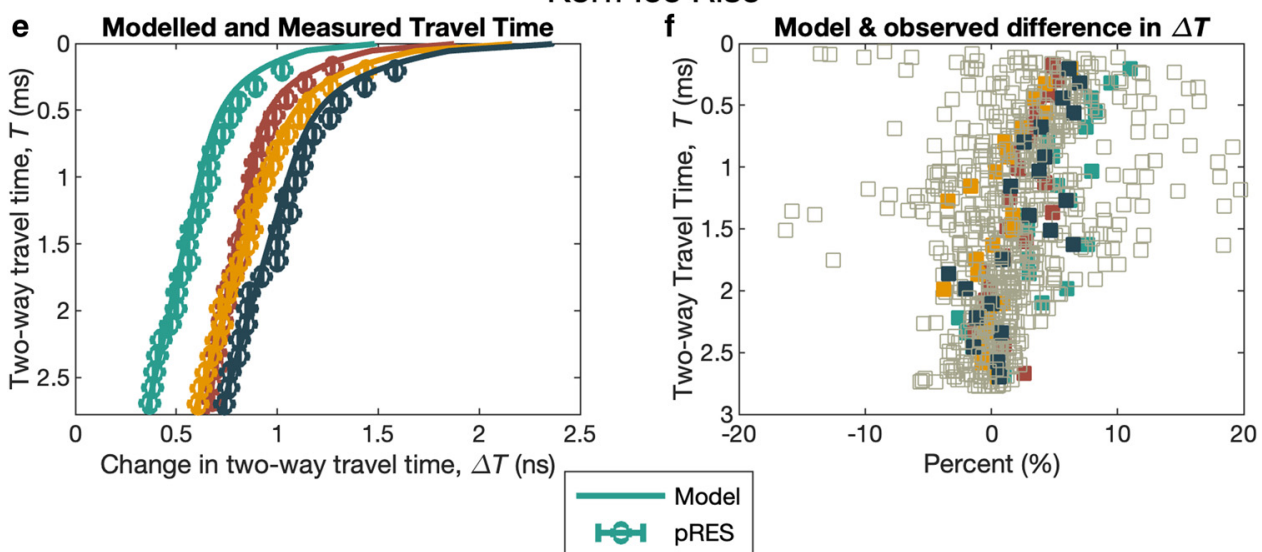

Fig. 6. Modeled (solid lines) and measured (circles) two-way travel time, $T$, and change in two-way travel times, $\Delta T$, at FP (a, b), SIR (c, d) and KIR (e, f). The left column shows $\Delta T$ as it changes with $T$ on FP (a) and at four randomly selected locations (differentiated by color) along SIR (c) and KIR (e). The model was run with activation energies obtained by optimizing the model output to the results of Method 1 . The right column shows the normalized mismatch in $\Delta T$, $\left(\Delta T-\Delta T_{\mathrm{m}}\right) / \Delta T$ ), as a percentage. The colors correspond to the randomly selected locations shown in the left panels, and the gray boxes show the normalized mismatch at all other locations along the transects of KIR and SIR. $\Delta T$ and $\Delta T_{\mathrm{m}}$ agree at all locations and depths to within $20 \%$. At FP, the model overestimates $\Delta T$ in the top $30 \mathrm{~m}$. Note the variable horizontal axes in the left panels.

thinning the firn pack enough to influence subglacial hydrology (Alley and Bentley, 1988; Riverman and others, 2019). Future research could take into account all stresses that potentially contribute to firn compaction by using a compressible, full-Stokes flow model (e.g. Licciulli and others, 2020) and including a compressible, full-Stokes stress balance in minimization of Method 2, i.e. requiring that the derived firn compaction rates obey this stress balance as well as mass conservation.

A different, related issue is estimating horizontal strain rates. This is a significant source of uncertainty in our estimates of firn compaction rates and is relevant to all of our methods for analyzing pRES data. The SIA (Lliboutry, 1979) predicts approximately vertically uniform horizontal strain rates above the bed and has been applied to cold-based ice rise flanks before (Martín and others, 2012; Kingslake and others, 2014; Wearing and Kingslake, 2019). This motivates our decision to estimate the horizontal strain rate from the slope of a linear fit to pRES-measured vertical velocity profiles in the middle third of the ice column. However, pRES-measured vertical velocities deviate from linear in this region due either to erroneous vertical variability (i.e. noise; Kingslake and others, 2014) in the data, or true variability not accounted for by the SIA, so the choice of upper and lower bounds on the linear fit introduces some uncertainty. For example, varying the upper and lower bounds by $\pm 25 \mathrm{~m}$ changes our estimates of the vertical strain rate by up to $14 \%$ at FP, and by a similar amount elsewhere. This uncertainty propagates into all three of our methods. In Method 1, we removed the contribution of the horizontal strain rates to isolate firn compaction (Section 2.3.1); in Section 2.7, we added this contribution to our modeled firn compaction velocities to compare model outputs with radar observations. Estimates of firn compaction and density produced by Method 2 are affected in a particularly complex way 
by this uncertainty because we use $\dot{\epsilon}_{x}$ as an input to the minimization, which in turn impacts the optimal values for the surface density, density decay length and surface velocity. For example, at FP, a $14 \%$ change in $\dot{\epsilon}_{x}$ leads to a $16 \%$ change in the density at $30 \mathrm{~m}$ but less than a $1 \%$ change in velocity at the same depth. This is largely driven by the inverted velocity's insensitivity to the decay length, $L-$ a $14 \%$ change in $\dot{\epsilon}_{x}$ can lead to up to a $65 \%$ change in $L$, which in turn affects the resulting density profile (Eqn (7)).

We explored a variety of alternative approaches to address uncertainty associated with estimating $\dot{\epsilon}_{x}$. For example, instead of the three-parameter minimization of Method 2 (Section 2.3.2), we can consider $\dot{\epsilon}_{x}$ unknown and optimize Eqn (11) for four parameters instead of three. This four-parameter inversion produces a good fit for ice-equivalent velocity $\left(\omega_{\mathrm{i}}\right)$; however, its insensitivity to $L$ causes a large mismatch to the measured density, which translates into a worse match to the velocity $W$ estimated with Method 1 (Eqn (4)), and thus the compaction velocity $W_{\mathrm{c}}$ (Fig. 3). This is because computing $\dot{\epsilon}_{x}$ from a linear fit to a region below the firn and prescribing this value in Method 2 is equivalent to performing the four-parameter inversion while, in effect, restricting the depth range used for the estimation of $\dot{\epsilon}_{x}$. In other words we more closely match pRES observations when we prevent the inversion from erroneously using velocity observations from shallower or deeper depths in its estimation of $\dot{\epsilon}_{x}$, where $\dot{\epsilon}_{z}$ is not uniform. Another alternative is estimating horizontal strain rates from repeat GNSS surveys of poles installed in the ice surface. Kingslake and others (2016) conducted such a survey on KIR. We find that applying Method 2 to the KIR data using either the point-by-point GNSS-derived horizontal strain rates or a spatially averaged value leads to velocities and densities with higher mismatches to pRES observations and core measurements than either the four-parameter minimization, described above or Method 2. Given these considerations, we suggest that estimating $\dot{\epsilon}_{x}$ with a linear fit and employing Method 2 while optimizing for the remaining three parameters (as described in Section 2.3.2) is a reasonable choice, despite the uncertainty associated with selecting the vertical bounds on the linear fit. This simple approach also has the advantage that it can be applied to pRES data collected in locations without surface velocity measurements.

Firn density is required to translate pRES-observed two-way travel time $(T)$ into depth, and the change in two-way travel time $(\Delta T)$ into velocities. Where independent density measurements are absent, we can invert for density using Method 2. When applied to pRES data collected near ice-core sites on FP and SIR, Method 2 produces vertical compaction rates that broadly agree with modeled compaction rates and with the results of Method 1 (which uses the ice core-derived density profiles). It also produces densities that broadly agree with ice core-measured densities at FP. However, because of our choice of a simple exponential function to describe the vertical variation of density, Method 2 consistently underestimates the density of deeper firn. Moreover, in some cases the minimization entirely fails to retrieve accurate density profiles when pRES measurements deviate significantly from the smooth vertical variation in $\Delta T$ expected from viscous ice flow and viscous-like compaction. In general, this impacts the estimate of the horizontal strain rate, which propagates through the inversion. For example, at SIR, Method 2 yields unrealistically high values of $L$ and a poor fit to ice coremeasured densities. Future research could address this limitation using a more complex description of the vertical variation of density, incorporating other geophysical surface measurements to add constraints on density, or imposing surface densities measured in the field (Fausto and others, 2018) or estimated with a climate model (Alexander and others, 2019).

A final limitation of pRES (and its successor, ApRES) is that it was not designed to measure strain rates at depths shallower than $\sim 10-15 \mathrm{~m}$, which is where all or a majority of the first stage of densification $\left(\rho<550 \mathrm{~kg} \mathrm{~m}^{-3}\right)$ occurs. The depth range covered by pRES can potentially complement shallower strain-rate measurements made in boreholes. The advantages to measuring deep strain rates include allowing the removal of horizontal strain rates from firn compaction estimates. However, future attempts to obtain better radar-based constraints on the early stages of densification could involve redesigning the radar system to specifically target shallower firn.

We compared our results to the densification model from Arthern and others (2010) because it integrates most of the known firn-compaction physics (e.g. grain sintering and growth, compaction due to overburden stress and heat flow). However, previous research has shown that this model displays some characteristics seemingly at odds with observations; for example, steady-state densities are only weakly dependent on accumulation rate (Lundin and others, 2017). Nonetheless, we compared the firn model to our observations of density and firn compaction and found close agreement between model results and the pRES observations after tuning model activation energies to the observations, giving us some confidence that the signal we have extracted from the pRES measurements accurately reflects firn compaction velocities.

Where pRES measurements of firn compaction and ice corederived densities coincide, we have the choice of tuning activation energies to the compaction measurements or to the densities. Most firn densification models currently tune activation energies to firn cores. At SIR and FP, the activation energies tuned to either density or compaction agree to within $1 \mathrm{~kJ}$, which indicates that both pRES and ice cores can be used to tune models of firn compaction. The activation energies we find to be optimal (Section 3.3) are larger than those used by Arthern and others (2010). The magnitudes of $E_{\mathrm{c}}$ fall within the range of low-temperature $\left(<-10^{\circ} \mathrm{C}\right)$ activation energies for volume selfdiffusion estimated from in situ observations or laboratory experiments on ice (Weertman, 1983, their Table 3), although exceed the average value $\left(59 \mathrm{~kJ} \mathrm{~mol}^{-1}\right)$. The magnitudes of $E_{\mathrm{g}}$ exceed the commonly used value for grain-boundary diffusion inferred from polar firn (42.4 $\mathrm{kJ} \mathrm{mol}^{-1}$; Cuffey and Paterson, 2010)) and measured in laboratory experiments $\left(40.6 \mathrm{~kJ} \mathrm{~mol}^{-1}\right.$; Cuffey and Paterson, 2010). This mismatch may indicate other grain processes at work, or sensitivities that are not included in this model. Although activation energies encapsulate the sensitivity of a process to temperature, they themselves may be temperaturedependent (Li and Zwally, 2004) and affected by the presence of impurities (e.g. Freitag and others 2013). We ignored these effects and future research under controlled laboratory circumstances may be needed to disentangle them.

As in the low-density regime of the widely used Herron and Langway (1980) firn model, the steady-state density predicted by the model proposed by Arthern and others (2010) is largely independent of the accumulation rate (Lundin and others, 2017). This is a result of a tradeoff: in a steady-state, high accumulation rates bury low-density, small-grained snow faster, tending to lower the density at a given depth through advection (second term on the right side of Eqn (15)). However, because compaction rates are inversely proportional to grain size, this small-grained snow compacts faster (Eqn (15)). In this model, these processes compensate for each other, reducing the sensitivity of steady-state densities to accumulation. Ligtenberg and others (2014) addressed an apparent discrepancy between this model behavior and observations by adding an accumulation-dependent factor, but accumulation dependence remains a source of disagreement among models (Lundin and others, 2017). In future research, widespread, long-term (multi-year) phase-sensitive radar measurements may help untangle the relationship between temperature, accumulation, 
density and densification rate by taking measurements at locations with similar average temperatures but varying accumulation rates, and vice versa.

\section{Conclusions}

The pRES and its update, the ApRES, have been deployed widely across Antarctica, Greenland and elsewhere to measure basal melt rates (Corr and others, 2002; Jenkins and others, 2006; Nicholls and others, 2015), ice fabric (Jordan and others, 2020; Young and others, 2021), englacial velocities (Kingslake and others, 2014, 2016) and glacial hydrology (Vaňková and others, 2018). As our study demonstrates, these systems also record firn densification.

We presented two methods for extracting firn compaction information from phase-sensitive radar data, and an additional method for comparing compaction models to pRES observations. Despite uncertainty about the contribution of ice flow to vertical velocity and limited observations in the upper 10-15 $\mathrm{m}$, these methods generate compaction rates in close agreement with the steady-state output of a physics-based firn model. This gives us some confidence that the signal we are extracting from the pRES measurements is an accurate representation of firn compaction. However, we require coincident pRES (or ApRES) and independent firn compaction measurements (perhaps from downborehole instrumentation) to fully validate this approach.

We highlighted three surveys in the Weddell Sea sector. Other, more spatially widespread and/or temporally near-continuous pRES/ApRES measurements performed primarily for other purposes may contain valuable information about firn compaction. In particular, pRES/ApRES measurements that coincide with density profiles could help constrain firn models, and ultimately improve estimates of mass balance from altimetry and climate reconstructions from ice cores.

Of particular interest to the firn modeling community is the temporal and spatial variability of densification and the dependence of firn density on the accumulation rate (Lundin and others, 2017). For example, Arthern and others (2010) took continuous measurements of compaction velocities, which varied by an order of magnitude between sites and by a factor of five at the same site over a few years. Others have modeled the influence of seasonal temperature variation on compaction (Zwally and Li, 2002; $\mathrm{Li}$ and Zwally, 2004; Li and others, 2007) and observed impurity-related (Hörhold and others, 2012; Freitag and others, 2013) changes in compaction. Phase-sensitive radars offer the community an opportunity for long-term, near-continuous measurements of compaction rates, which can be leveraged to clarify the impact of temperature and accumulation rate changes on firn compaction.

Acknowledgements. The authors thank R. Mulvaney, British Antarctic Survey (BAS), for supplying ice density data, and Rob Arthern, Carlos Martin, Hugh Corr and Richard Hindmarsh, for assistance with field survey design and operation of the pRES system, mentoring of JK, and discussion of the firn model and inverse methods. pRES and GNSS data are available from the UK Polar Data Center (http://doi.org/99b and http://doi.org/99c). The fieldwork was funded by Natural Environmental Research Council grant NE/J008087/1, led by Richard Hindmarsh, BAS. Logistical support was provided by many members of the British Antarctic Survey's air unit and field operations team. The authors thank particularly Iain Rudkin and Scott Webster for their assistance in the field, Melchior van Wessem for providing the RACMO2.3p2 data, and Ian Hewitt, Tun Jan (TJ) Young and an anonymous reviewer for their excellent feedback, which greatly improved this publication. We acknowledge the Norwegian Polar Institute's Quantarctica package for use in creating Fig. 1. We also acknowledge funding from National Science Foundation grants 1738934 and 1935438. This paper is based upon work supported by the National Science Foundation Graduate Research Fellowship Program under Grant No. (1644869). Any opinions, findings and conclusions or recommendations expressed in this paper are those of the author(s) and do not necessarily reflect the views of the National Science Foundation. The associated code and data are available for download at https:/github.com/elizabethcase/pRES-firn-compaction-methods (doi: 10.5281/ zenodo.5090283)

\section{References}

Alexander PM, Tedesco M, Koenig L and Fettweis X (2019) Evaluating a regional climate model simulation of Greenland ice sheet snow and firn density for improved surface mass balance estimates. Geophysical Research Letters 46(21), 12073-12082. doi: 10.1029/2019GL084101

Alley RB (1987) Firn densification by grain-boundary sliding: a first model. Le Journal de Physique Colloques 48(C1), C1-249-C1-256. doi: 10.1051/ jphyscol:1987135

Alley RB and Bentley CR (1988) Ice-core analysis on the Siple coast of west Antarctica. Annals of Glaciology 11, 1-7. doi: 10.3189/S0260305500006236

Alley RB, Bolzan JF and Whillans IM (1982) Polar firn densification and grain growth. Annals of Glaciology 3, 7-11. doi: 10.3189/S0260305500002433

Arnaud L, Barnola JM and Duval P (2000) Physical modeling of the densification of snow/firn and ice in the upper part of polar ice sheets. Physics of Ice Core Records, 285-305.

Arthern RJ, Vaughan DG, Rankin AM, Mulvaney R and Thomas ER (2010) In situ measurements of Antarctic snow compaction compared with predictions of models. Journal of Geophysical Research: Earth Surface 115(F3), F03011. doi: 10.1029/2009JF001306

Arthern RJ and Wingham DJ (1998) The natural fluctuations of firn densification and their effect on the geodetic determination of ice sheet mass balance. Climatic Change 40(3), 605-624. doi: 10.1023/A:1005320713306

Bender M, Sowers T and Brook E (1997) Gases in ice cores. Proceedings of the National Academy of Sciences 94(16), 8343-8349. doi: 10.1073/pnas.94.16.8343

Brennan PV, Lok LB, Nicholls K and Corr H (2014) Phase-sensitive FMCW radar system for high-precision Antarctic ice shelf profile monitoring. Sonar Navigation IET Radar 8(7), 776-786. doi: 10.1049/iet-rsn.2013.0053

Brisbourne AM and 5 others (2019) Constraining recent ice flow history at Korff Ice Rise, West Antarctica, using radar and seismic measurements of ice fabric. Journal of Geophysical Research: Earth Surface 124(1), 175-194. doi: 10.1029/2018JF004776

Buizert C and 16 others (2015) The WAIS divide deep ice core WD2014 chronology - part 1: methane synchronization (68-31 ka BP) and the gas age-ice age difference. Climate of the Past 11(2), 153-173. doi : 10.5194/ cp-11-153-2015.

Corr HFJ, Jenkins A, Nicholls KW and Doake CSM (2002) Precise measurement of changes in ice-shelf thickness by phase-sensitive radar to determine basal melt rates. Geophysical Research Letters 29(8), 73-71. doi: 10.1029/ 2001GL014618

Craig H, Horibe Y and Sowers T (1988) Gravitational separation of gases and isotopes in polar ice caps. Science (New York, N.Y.) 242(4886), 1675-1678. doi: $10.1126 /$ science.242.4886.1675

Cuffey KM and Paterson WSB (2010) The Physics of Glaciers. 4th Edn. Burlington, MA: Academic Press..

de la Peña $\mathbf{S}$ and 8 others (2015) Changes in the firn structure of the western Greenland ice sheet caused by recent warming. The Cryosphere 9(3), 12031211. doi: 10.5194/tc-9-1203-2015.

Fausto RS and 11 others (2018) A snow density dataset for improving surface boundary conditions in Greenland ice sheet firn modeling. Frontiers in Earth Science 6, 51. doi: 10.3389/feart.2018.00051.

Freitag J, Kipfstuhl S, Laepple T and Wilhelms F (2013) Impurity-controlled densification: a new model for stratified polar firn. Journal of Glaciology 59 (218), 1163-1169. doi: 10.3189/2013JoG13J042

Gillet-Chaulet F, Hindmarsh RCA, Corr HFJ, King EC and Jenkins A (2011) In-situ quantification of ice rheology and direct measurement of the Raymond Effect at Summit, Greenland using a phase-sensitive radar. Geophysical Research Letters 38(24), L24503. doi: 10.1029/2011GL049843.

Goujon C, Barnola J-M and Ritz C (2003) Modeling the densification of polar firn including heat diffusion: application to close-off characteristics and gas isotopic fractionation for Antarctica and Greenland sites. Journal of Geophysical Research: Atmospheres 108(D24), 4792. doi: 10.1029/2002JD003319.

Hanna E and 11 others (2013) Ice-sheet mass balance and climate change. Nature 498(7452), 51-59. doi: 10.1038/nature12238.

Haran T, Bohlander J, Scambos T, Painter T and Fahnestock M (2021, updated 2019) MODIS Mosaic of Antarctica 2003-2004 (MOA2004) Image Map, Version 2. Boulder, Colorado USA. NASA National Snow 
and Ice Data Center Distributed Active Archive Center. Accessed April 2021. doi: 10.5067/68TBT0CGJSOJ.

Helm V, Humbert A and Miller H (2014) Elevation and elevation change of Greenland and Antarctica derived from CryoSat-2. The Cryosphere 8, 15391559. doi: $10.5194 /$ tc-8-1539-2014

Helsen MM and 7 others (2008) Elevation changes in Antarctica mainly determined by accumulation variability. Science 320(5883), 1626-1629. doi: $10.1126 /$ science. 1153894 .

Herron MM and Langway CC (1980) Firn densification: an empirical model. Journal of Glaciology 25(93), 373-385. doi: 10.3189/\$0022143000015239

Hindmarsh RCA and 5 others (2011) Flow at ice-divide triple junctions: 2. Three-dimensional views of isochrone architecture from ice-penetrating radar surveys. Journal of Geophysical Research: Earth Surface 116(F2), F02024. doi: 10.1029/2009JF001622.

Hörhold MW and 5 others (2012) On the impact of impurities on the densification of polar firn. Earth and Planetary Science Letters 325-326, 93-99. doi: 10.1016/j.epsl.2011.12.022

Howat IM, Porter C, Smith BE, Noh M-J and Morin P (2019) The reference elevation model of Antarctica. The Cryosphere 13(2), 665-674. doi: 10.5194/ tc-13-665-2019

Jenkins A, Corr HFJ, Nicholls KW, Stewart CL and Doake CSM (2006) Interactions between ice and ocean observed with phase-sensitive radar near an Antarctic ice-shelf grounding line. Journal of Glaciology 52(178), 325-346. doi: 10.3189/172756506781828502

Jordan TM, Schroeder DM, Elsworth CW and Siegfried MR (2020) Estimation of ice fabric within Whillans Ice Stream using polarimetric phase-sensitive radar sounding. Annals of Glaciology 61(81), 74-83. doi: 10.1017/aog.2020.6

Kendrick AK and 12 others (2018) Surface meltwater impounded by seasonal englacial storage in west Greenland. Geophysical Research Letters 45(10), 474-481. doi: 10.1029/2018GL079787.

Kingslake J and 12 others (2014) Full-depth englacial vertical ice sheet velocities measured using phase-sensitive radar. Journal of Geophysical Research: Earth Surface 119(12), 2014JF003275. doi: 10.1002/2014JF003275.

Kingslake J, Martín C, Arthern RJ, Corr HFJ and King EC (2016) Ice-flow reorganization in west Antarctica $2.5 \mathrm{kyr}$ ago dated using radar-derived englacial flow velocities. Geophysical Research Letters 43(17), 2016GL070278. doi: 10.1002/2016GL070278

Kovacs A, Gow A and Morey R (1995) The in-situ dielectric constant of polar firn revisited. Cold Regions Science and Technology 23(3), 245-256. doi: 10. 1016/0165-232X(94)00016-Q

Li J and Zwally HJ (2002) Modeled seasonal variations of firn density induced by steady-state surface air-temperature cycle. Annals of Glaciology 34, 299302. doi: $10.3189 / 172756402781817707$

Li J and Zwally HJ (2004) Modeling the density variation in the shallow firn layer. Annals of Glaciology 38, 309-313. doi: 10.3189/172756404781814988

Li J, Zwally HJ and Comiso JC (2007) Ice-sheet elevation changes caused by variations of the firn compaction rate induced by satellite-observed temperature variations (1982-2003). Annals of Glaciology 46, 8-13. doi: 10. $3189 / 172756407782871486$

Licciulli C and 5 others (2020) A full Stokes ice-flow model to assist the interpretation of millennial-scale ice cores at the high-alpine drilling site Colle Gnifetti, Swiss/Italian Alps. Journal of Glaciology 66(255), 35-48. doi: 10. 1017/jog.2019.82

Ligtenberg SRM, Kuipers MP and van den Broeke MR (2014) Present and future variations in Antarctic firn air content. The Cryosphere 8(5), 17111723. doi: 10.5194/tc-8-1711-2014

Lliboutry L (1979) Critical review of analytical approximate solutions for steady-state velocities and temperatures in cold ice sheets. Zeitschrift fuer Gletscherkunde und Glazialgeologie 15(2), 135-148.

Lundin JMD and 12 others (2017) Firn model intercomparison experiment (FirnMICE). Journal of Glaciology 63(239), 401-422. doi: 10.1017/jog.2016.114.

Martín C and Gudmundsson GH (2012) Effects of nonlinear rheology, temperature and anisotropy on the relationship between age and depth at ice divides. The Cryosphere 6, 1221-1229. doi: 10.5194/tc-6-1221-2012.

Matsuoka K and 19 others (2015) Antarctic ice rises and rumples: their properties and significance for ice-sheet dynamics and evolution. Earth-Science Reviews 150, 724-745. doi: 10.1016/j.earscirev.2015.09.004.

Medley B and 5 others (2015) Antarctic firn compaction rates from repeattrack airborne radar data: I. Methods. Annals of Glaciology 56(70), 155-166. doi: 10.3189/2015AoG70A203
Meyer CR, Keegan KM, Baker I and Hawley RL (2020) A model for French-press experiments of dry snow compaction. The Cryosphere 14(5), 1449-1458. doi: 10.5194/tc-14-1449-2020

Morris EM and 9 others (2017) Snow densification and recent accumulation along the iSTAR traverse, pine island glacier, Antarctica: snow densification. Journal of Geophysical Research: Earth Surface 122(12), 2284-2301. doi: 10. 1002/2017JF004357.

Morris EM (2018) Modeling dry-snow densification without abrupt transition. Geosciences 8(12), 464. doi: 10.3390/geosciences8120464

Morris EM and Wingham DJ (2014) Densification of polar snow: measurements, modeling, and implications for altimetry. Journal of Geophysical Research: Earth Surface 119(2), 349-365. doi: 10.1002/ 2013JF002898

Mouginot J, Scheuchl B and Rignot E (2017) MEaSUREs Antarctic Boundaries for IPY 2007-2009 from Satellite Radar, Version 2. Boulder, Colorado USA. NASA National Snow and Ice Data Center Distributed Active Archive Center. Accessed April 2021. doi: 10.5067/ AXE4121732AD.

Mulvaney R, Rix J, Polfrey S, Grieman M, Martìn C, Nehrbass-Ahles C, Rowell I, Tuckwell R and Wolff E (2021) Ice drilling on Skytrain Ice Rise and Sherman Island, Antarctica. Annals of Glaciology, 1-13. doi: 10. 1017/aog.2021.7

Mulvaney R, Triest J and Alemany O (2014) The James Ross Island and the fletcher promontory ice-core drilling projects. Annals of Glaciology 55(68), 179-188. doi: 10.3189/2014AoG68A044

Nicholls KW and 5 others (2015) A ground-based radar for measuring vertical strain rates and time-varying basal melt rates in ice sheets and shelves. Journal of Glaciology 61(230), 1079-1087. doi: 10.3189/2015JoG15J073

Paterson WSB (1994) Physics of Glaciers., 3rd edn, Oxford.: ButterworthHeinemann.

Raymond C and 5 others (1996) Geometry, motion and mass balance of dyer plateau, Antarctica. Journal of Glaciology 42(142), 510-518. doi: 10.3189/ S002214300000349X

Riverman KL and 7 others (2019) Enhanced firn densification in high-accumulation shear margins of the NE Greenland Ice Stream. Journal of Geophysical Research: Earth Surface 124, 365-382. doi: 10.1029/ $2017 J F 004604$.

Salamatin AN and 5 others (2009) Snow/firn densification in polar ice sheets. Low Temperature Science 68(Supplement Issue), 28.

Severinghaus JP and Brook EJ (1999) Abrupt climate change at the end of the last glacial period inferred from trapped air in polar ice. Science 286(5441), 930-934. doi: $10.1126 /$ science.286.5441.930

Shepherd A and 46 others (2012) A reconciled estimate of Ice-sheet mass balance. Science 338(6111), 1183-1189. doi: 10.1126/science.1228102.

Smith B and 14 others (2020) Pervasive ice sheet mass loss reflects competing ocean and atmosphere processes. Science 368(6496), 1239-1242. doi: 10. $1126 /$ science.aaz5845.

Vaňková I and 5 others (2018) Vertical structure of diurnal englacial hydrology cycle at Helheim glacier, east Greenland. Geophysical Research Letters 45(16), 8352-8362. doi: 10.1029/2018GL077869

van Wessem JM and 18 others (2018) Modelling the climate and surface mass balance of polar ice sheets using RACMO2 - Part 2: Antarctica (19792016). The Cryosphere 12, 1479-1498. doi: 10.5194/tc-12-1479-2018.

WAIS Divide Project Members (2015) Precise interpolar phasing of abrupt climate change during the last ice age. Nature 520(7549), 661-665. doi: 10.1038/nature14401

Wearing MG and Kingslake J (2019) Holocene formation of Henry Ice Rise, West Antarctica, inferred from ice-penetrating radar. Journal of Geophysical Research: Earth Surface 124(8), 2224-2240. doi: 10.1029/ 2018JF004988

Weertman J (1983) Creep Deformation of Ice. Annual Review of Earth and Planetary Sciences 11, 215-240. doi: https://doi.org/10.1146/annurev.ea.11. 050183.001243.

Young TJ and 5 others (2021) Rapid and accurate polarimetric radar measurements of ice crystal fabric orientation at the Western Antarctic Ice Sheet (WAIS) Divide ice core site. The Cryosphere Discussions 15, 41174133. doi: $10.5194 / \mathrm{tc}-15-4117-2021$

Zwally HJ and Li J (2002) Seasonal and interannual variations of firn densification and ice-sheet surface elevation at the Greenland summit. Journal of Glaciology 48(161), 199-207. doi: 10.3189/172756502781831403 